\title{
有限水深の波による円柱状浮体の運動 \\ ON THE MOTIONS OF A FLOATING CIRCULAR CYLINDER \\ IN WAVES OF FINITE WATER DEPTH
}

井島 武 士* ・田淵 幹修**.湯 村 やす***

By Takeshi Ijima, Yoshinobu Tabuchi and Yasu Yumura

\section{1.はしがき}

有限水深の海面付近に固定された円柱状物体による波 の変形について Miles ${ }^{1)}$ は変分法により解析し, Garrett ${ }^{2)}$ は本文に述べると類似の方法で問題を解析し, Miles の 計算の誤りを修正した。また Black, Mei \& $\mathrm{Bray}^{3)}$ は, 水面または水底付近の矩形断面物体および円柱状物体の 微小強制運動による radiation wave の発生を積分方程 式を解くことにより解析している。

著者ら ${ }^{4)}$ は前論文において, 矩形断面物体が有限水樑 の海域に繋留されている場合と自由に運動する場合につ いて, 物体の運動を流体運動の境界值問題におきかえて 解析する方法を述べたが，ここでは同様の方法を抾張し て円柱状物体が慗留されているとき, 一方向からの波の 入射によって生ずる物体の運動を解析する方法を示し, その特別な場合として自由運動を含めて計算結果を示す ことにする。

本文では一方向からの入射波を与えて, 対応する物体 運動を求める方法を示しているが, その応用として物体 に強制運動を与えたときに発生する radiation wave お よび物体に作用する流体力を計算することができ，いわ ゆる付加質量力（または付加慣性モーメント）と減衰力 （または減衰力モーメント）が求められ，また物体を固 定したとき, 入射波によって生ずる散乱波, 反射波, 物 体に作用する流体力などを求めることもできる。ここで は前者についての計算例を示す。

\section{2. 解 析 法}

Fig. 1 に示すように, 一定水深 $h$ の海域に半径 $a$ の

\begin{tabular}{|c|c|c|c|}
\hline * 正会員 & 工博 & 九州大学教授 & 工学部水工士木学科 \\
\hline ** 正会員 & & 九州大学助手 & 同 \\
\hline *** & & 九州大学助手 & 同 \\
\hline
\end{tabular}

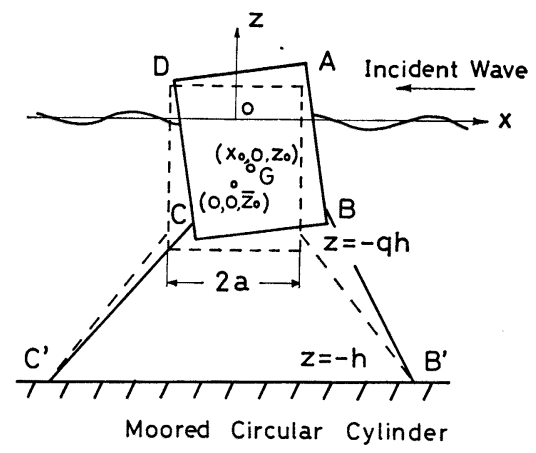

Fig. 1

円柱状浮体が下端 $\mathrm{B}, \mathrm{C}$ の 2 点で対称な形で繋留されて おり, 右方からの周波数 $\sigma(=2 \pi / T, T$ は波の周期 $)$ の 入射波により運動する場合を考える。静止時の物体の吃 水は $q h(1>q>0)$ で, 重心は水面から $\bar{z}_{0}$ の深さに あり, 索の着力点は重心から $h_{1}$ だけ下にあるとする。 座標系は静水面に原点 $\mathrm{O}$ をり, 鉛直上方に $z$ 軸, 入射 波の進行方向に $x$ 軸 (向きは逆) 直角方向に $y$ 軸を取 る。流体運動は非圧縮性完全流体における 3 次元の速度 ポテンシャルをもつ微小振幅波運動とする。円柱座標を 用い $x=r \cos \theta, y=r \sin \theta$ とすると, 速度ポテンシャ ルは $\Phi(r, \theta, z ; t)=\phi(r, \theta, z) e^{i \sigma t}$ と書かれ, $\phi(r, \theta, z)$ は次の Laplace の方程式を満足する。

$$
\frac{\partial^{2} \phi}{\partial r^{2}}+\frac{1}{r} \frac{\partial \phi}{\partial r}+\frac{1}{r^{2}} \frac{\partial^{2} \phi}{\partial \theta^{2}}+\frac{\partial^{2} \phi}{\partial z^{2}}=0
$$

\section{（1）境界条件式}

$x$ 方向からの入射波により, 円柱浮体は $x z$ 平面内で 微小運動を行ない, 静止時の重心位置 $\left(0,0, \bar{z}_{0}\right)$ は運動 の結果 $\left(x_{0}, 0, z_{0}\right)$ に移動し, 円柱は角度 $\delta$ だけ回転す るものとする。この水平と鉛直移動および回転角の複素 数振幅をそれぞれ $\xi, \eta, \omega$ とすると, 次の関係にある。

$$
x_{0}=\xi e^{i \sigma t}, z_{0}=\bar{z}_{0}+\eta e^{i \sigma t}, \delta=\omega e^{i \sigma t}
$$

この運動による円柱側面と底面の方程式は第 1 近似で 
はそれぞれ次のようである。

$$
\begin{aligned}
& x^{2}+y^{2}-a^{2}-2 x\left\{\xi+\left(\bar{z}_{0}-z\right) \omega\right\} e^{i \sigma t}=0 \cdots \cdots(3) \\
& z+q h-(\eta+\omega x) e^{i \sigma t}=0 \cdots \cdots \cdots \cdots \cdots \cdots \cdots \cdots(4)
\end{aligned}
$$

ゆえに物体の没水表面に扔ける運動学的境界条件は次 のようになる。

$$
\begin{aligned}
& r=a, 0>z>-q h \text { で } \\
& \partial \phi / \partial r=i \sigma\left\{\xi+\left(\bar{z}_{0}-z\right) \omega\right\} \cos \theta \\
& z=-q h, r<a \text { で } \\
& \partial \phi / \partial z=i \sigma(\eta+\omega r \cos \theta) \ldots \ldots . .
\end{aligned}
$$

\section{（2）流体運動の速度ポテンシャル}

流体域を内域（円柱下部の領域， $r \leqq a ）$ と外域（円 柱の外側の領域, $r \geqq a$ ) とに分け, 各領域の速度ポテ ンシャルをそれぞれ $\phi_{1}(r, \theta, z), \phi_{2}(r, \theta, z)$ とする。

\section{a) $\phi_{1}(r, \theta, z)$}

重力の加速度を $g$ とすると， $\phi_{1}$ に対する水面と水底 の境界条件は次のようである。

$$
\begin{aligned}
& z=0 \text { で } \partial \phi_{1} / \partial z=\sigma^{2} \phi_{1} / g \\
& z=-h \text { で } \partial \phi_{1} / \partial z=0 \cdots
\end{aligned}
$$

上式を满足する Laplace の方程式の解として $\phi_{1}$ は次 のように与えられる。

$$
\begin{aligned}
\phi_{1}(r, \theta, z)= & \sum_{m=0}^{\infty}\left[\left(A_{m 0} \frac{J_{m}(k r)}{J_{m}(k a)}\right.\right. \\
& \left.+B_{m 0} \frac{H_{m}^{(2)}(k r)}{H_{m}^{(2)}(k a)}\right) \frac{\cosh k(z+h)}{\cosh k h} \\
& \left.+\sum_{n=1}^{\infty} C_{m n} \frac{K_{m}\left(k_{n} r\right)}{K_{m}\left(k_{n} a\right)} \frac{\cos k_{n}(z+h)}{\cos k_{n} h}\right] . \\
& \cdot \cos m \theta \ldots \ldots \ldots \ldots \ldots \ldots \ldots \ldots \ldots(9)
\end{aligned}
$$

ここで $m$ は整数で, $k$ および $k_{n}$ は次式で決まる固有 值である。

$$
\sigma^{2} h / g=k h \tanh k h=-k_{n} h \tan k_{n} h(n=1,2,3 \cdots)
$$

$J_{m}$ および $H_{m}{ }^{(2)}$ はそれぞれ $m$ 次の第 1 種および第 3 種ベッセル関数（第 2 種ベッセル関数を $N_{m}$ とすると $\left.H_{m}{ }^{(2)}=J_{m}-i N_{m}\right), K_{m}$ は $m$ 次の変形ベッセル関数で ある。 $A_{m 0}, B_{m 0}, C_{m n}$ は任意定数で，それぞれ入射波と 円柱による進行散乱波および停止散乱波を表わす。

$$
\text { 水面波形は } \zeta=-\frac{1}{g}(\partial \Phi / \partial t)_{z=0} \text { で与えられ, 式 (9) }
$$
から次のようになる。

$$
\begin{aligned}
\zeta(r, \theta ; t)= & -\frac{i \sigma}{g} \sum_{m=0}^{\infty}\left(A_{m 0} \frac{J_{m}(k r)}{J_{m}(k a)}\right. \\
& \left.+B_{m 0} \frac{H_{m}{ }^{(2)}(k r)}{H_{m}^{(2)}(k a)}+\sum_{n=1}^{\infty} C_{m n} \frac{K_{m}\left(k_{n} r\right)}{K_{m}\left(k_{n} a\right)}\right) . \\
& \cdot \cos m \theta \cdot e^{i \sigma t} \ldots \ldots \ldots \ldots \ldots \ldots \ldots \ldots \ldots \ldots \ldots(11)
\end{aligned}
$$

入射波を $\zeta_{i}=\zeta_{0} \cos (k x+\sigma t)$ とすると， $\zeta_{i}=\zeta_{0} R e^{i k x}$. $e^{i \sigma t}$ であるが

$$
\begin{aligned}
e^{i k x} & =e^{i k r \cos \theta}=\sum_{m=0}^{\infty} \varepsilon_{m} i^{m} J_{m}(k r) \cos m \theta, \\
\left(\varepsilon_{0}\right. & \left.=1, \varepsilon_{m}=2(m \neq 0)\right) \cdots \ldots \ldots \ldots \ldots \ldots \ldots \ldots \ldots \ldots \ldots \ldots \ldots \ldots \ldots \ldots \ldots
\end{aligned}
$$

の関倸があるから, 式 (11) の右辺第 1 項と比較して, $A_{m 0}$ は次の関係で決まることになる。

$$
A_{m 0}=i^{m+1} \varepsilon_{m} J_{m}(k a) \cdot \zeta_{0} g / \sigma
$$

b) $\phi_{2}(r, \theta, z)$

内域の速度ポテンシャル $\phi_{2}$ に対する境界条件は式 (6) と水底条件とから次の上うになる。

$$
\begin{aligned}
& z=-q h \text { で } \partial \phi_{2} / \partial z=i \sigma(\eta+\omega r \cos \theta) \\
& z=-h \text { で } \partial \phi_{2} / \partial z=0 \text {. } \\
& \phi_{2}=\phi_{2}{ }^{(1)}+\phi_{2}{ }^{(2)}
\end{aligned}
$$$$
\text { ここで }
$$

とおき, $\phi_{2}^{(1)}$ に対しては

$$
z=-q h \text { および } z=-h \text { で } \partial \phi_{2}{ }^{(1)} / \partial z=0 \cdots(17)
$$

の条件を与えると式 (1) の一般解として $\phi_{2}{ }^{(1)}$ は次のよ うである。

$$
\begin{aligned}
\phi_{2}{ }^{(1)}(r, \theta, z)= & \sum_{m=0}^{\infty}\left\{D_{m 0}\left(\frac{r}{a}\right)^{m}+\sum_{s=1}^{\infty} D_{m s} \frac{I_{m}(\bar{s} r)}{I_{m}(\bar{s} a)} .\right. \\
& \cdot \cos \bar{s}(z+q h)\} \cos m \theta \cdots \cdots(18)
\end{aligned}
$$

ここで $I_{m}$ は $m$ 次の変形ベッセル関数で, $\bar{s}=s \pi / \bar{q} h$, $\bar{q}=1-q, s$ は整数である。

$\phi_{2}{ }^{(2)}$ に対しては式 (14)，(15) の条件を与え, 式 (14) の右辺を $a \geqq r \geqq 0$ でベッセル関数により展開すると

$$
\begin{aligned}
& i \sigma \eta=2 i \sigma \eta \sum_{s=1}^{\infty} \frac{J_{0}\left(\lambda_{0 s} r / a\right)}{\lambda_{0 s} J_{1}\left(\lambda_{0 s}\right)}, \\
& i \sigma \omega r \cos \theta=2 i \sigma \omega a \sum_{s=1}^{\infty} \frac{J_{1}\left(\lambda_{1 s} r / a\right)}{\lambda_{1 s} J_{2}\left(\lambda_{1 s}\right)} \cdot \cos \theta
\end{aligned}
$$

ここで $\lambda_{0 s}$ および $\lambda_{1 s}$ はそれぞれ $J_{0}(x)=0$ と $J_{1}(x)=$ 0 の第 $s$ 番目の根を表わす。すなわち

$$
J_{0}\left(\lambda_{0 s}\right)=0, J_{1}\left(\lambda_{1 s}\right)=0,(s=1,2,3 \cdots)
$$

によって決まる值である。ゆえに式 (14)，(15) を満た す式 (1) の特解として $\phi_{2}{ }^{(2)}$ は次のように求められる。

$$
\begin{aligned}
\phi_{2}^{(2)}(r, \theta, z)= & 2 i \sum_{s=1}^{\infty}\left\{\eta \sigma h \cdot \frac{a}{h} \frac{J_{0}\left(\lambda_{0 s} r / a\right)}{\lambda_{0 s}{ }^{2} J_{1}\left(\lambda_{0 s}\right)} \cdot\right. \\
& \cdot \frac{\cosh \left(\lambda_{0 s}(z+h) / a\right)}{\sinh \left(\bar{q} \lambda_{0 s} h / a\right)}+\omega \sigma a^{2} \cdot \\
& \cdot \frac{J_{1}\left(\lambda_{1 s} r / a\right)}{\lambda_{1 s}{ }^{2} J_{2}\left(\lambda_{1 s}\right)} \cdot \frac{\cosh \left(\lambda_{1 s}(z+h) / a\right)}{\sinh \left(\bar{q} \lambda_{1 s} h / a\right)} . \\
& \cdot \cos \theta\} \cdots \cdots \cdots \cdots \cdots \cdots \cdots \cdots(21)
\end{aligned}
$$

式（18）と（21）の和は式 (14)，(15）を満足する式 (1) の一般解として用いられる。すなわち

$$
\begin{aligned}
& \phi_{2}(r, \theta, z) \\
& =\sum_{m=0}^{\infty}\left\{D_{m 0}\left(\frac{r}{a}\right)^{m}+\sum_{s=1}^{\infty} D_{m s} \frac{I_{m}(\bar{s} r)}{I_{m}(\bar{s} a)} \cdot\right. \\
& \cdot \cos \bar{s}(z+q h)\} \cos m \theta+2 i \sum_{s=1}^{\infty}\left\{\eta \sigma h \frac{a}{h} \cdot\right. \\
& \quad \cdot \frac{J_{0}\left(\lambda_{0 s} r / a\right)}{\lambda_{0 s}{ }^{2} J_{1}\left(\lambda_{0 s}\right)} \frac{\cosh \left(\lambda_{0 s}(z+h) / a\right)}{\sinh \left(\bar{q} \lambda_{1 s} h / a\right)} \\
& \left.\quad+\omega \sigma a^{2} \frac{J_{1}\left(\lambda_{1 s} r / a\right)}{\lambda_{1 s}{ }^{2} J_{2}\left(\lambda_{1 s}\right)} \frac{\cosh \left(\lambda_{1 s}(z+h) / a\right)}{\sinh \left(\bar{q} \lambda_{1 s} h / a\right)} \cos \theta\right\}
\end{aligned}
$$




\section{（3） 円柱浮体の運動方程式}

慗留索を有しない自由浮体としての吃水を $\mu q h(1>$ $\mu>0)$ とするときは, 円柱の質量 $M$ と重心を通り $y$ 軸に平行な軸の周りの慣性能率 $I$ は流体密度 $\rho$ により, 次のようにおくことができる。

$$
M=\rho \pi a^{2} \mu q h, I=\nu^{2} \rho \frac{\pi a^{4}}{4} \cdot \mu q h\left\{1+\frac{1}{3}\left(\frac{\mu q h}{a}\right)^{2}\right\}
$$

ここで $\nu^{2}$ は円柱の物体密度の分布により決まる定数で ある。

円柱の側面と底面に作用する流体の変動圧力をそれぞ れ $p_{1}, p_{2}$ とすると, 円柱に対する流体圧力の水平およ び鉛直合力 $P_{H}, P_{V}$ と重心に関する回転モーメント $T$ は次のようである。

$$
\left.\begin{array}{rl}
P_{H}= & -\int_{-q h}^{0} \int_{-\pi}^{\pi} a p_{1} \cos \theta d \theta d z, \\
P_{V}= & \int_{-\pi}^{\pi} \int_{0}^{a} p_{2} r d r d \theta \\
T= & \int_{-q h}^{0} \int_{-\pi}^{\pi} a p_{1} \cdot\left(z-z_{0}\right) \cos \theta d \theta d z \\
& +\int_{0}^{a} \int_{-\pi}^{\pi} p_{2} x r d \theta d r
\end{array}\right\}
$$

微小運動においては慗留索の反力は円柱の変位と回転 角に比例すると考えられ, 単位の水平と鉛直変位および 回転角に対する 1 本の慗留索の水平と鉛直方向の反力お よび抵抗モーメントをそれぞれ $K_{x x}, K_{z x}, K_{\theta x} ; K_{x z}$, $K_{z z}, K_{\theta z} ; K_{x \theta}, K_{z \theta}, K_{\theta \theta}$ とすると, 対称な索で繋留さ れた円柱の運動方程式は, 索の運動に対する慣性質量と 流体抵抗の影響を無視すると次のようである。

$$
\left.\begin{array}{c}
M d^{2} x_{0} / d t^{2}=P_{H}-2 K_{x x} \cdot x_{0}-2 K_{x \theta} \cdot \delta \\
M d^{2} z_{0} / d t^{2}=P_{V}-2 K_{z z}\left(z_{0}-\bar{z}_{0}\right) \\
I d^{2} \delta / d t^{2}=T-2 K_{\theta x} \cdot x_{0}-2 K_{\theta \theta} \cdot \delta
\end{array}\right\}
$$

流体圧力 $p$ は速度ポテンシャル $\emptyset$ により

$$
p=-\rho \partial \Phi / \partial t-\rho g z
$$

として表わされるから, 式 (24) は式 (9)，(22)により 計算され，次のようである。

$$
\begin{aligned}
P_{H}= & i \rho \sigma \pi a h\left[\bar{e}_{0}\left(A_{10}+B_{10}\right)+\sum_{n=1}^{\infty} \bar{e}_{n} C_{1 n}\right] e^{i \sigma t} \\
P_{V}= & -i \rho \sigma \pi a^{2}\left[D_{00}+\sum_{s=1}^{\infty} \overline{f_{s}^{(1)}} D_{0 s}+4 i \eta \sigma h \cdot\right. \\
\cdot & \left.\left\{-\frac{1}{4 r}+\frac{a}{h} \sum_{s=1}^{\infty} \frac{\operatorname{coth}\left(\bar{q} \lambda_{0 s} h / a\right)}{\lambda_{0 s}{ }^{3}}\right\}\right] e^{i \sigma t} \\
T= & -i \rho \sigma \pi a h^{2}\left[\bar{g}_{0}\left(A_{10}+B_{10}\right)+\sum_{n=1}^{\infty} \bar{g}_{n} C_{1 n}\right. \\
& +\frac{1}{4}\left(\frac{a}{h}\right)^{2}\left(D_{10}+\sum_{s=1}^{\infty} \overline{f_{s}^{(2)}} D_{1 s}\right) \\
& +2 i\left(\frac{a}{h}\right)^{2} \omega \sigma a^{2}\left\{\frac{q}{r}\left(\frac{h}{a}\right)^{2}\left(\frac{\bar{z}_{0}}{a}+\frac{q h}{2 a}\right)\right. \\
& \left.\left.-\frac{h}{a} \frac{1}{8 r}+\sum_{s=1}^{\infty} \frac{\operatorname{coth}\left(\bar{q} \lambda_{1 s} h / a\right)}{\lambda_{1 s}}\right\}\right] e^{i \sigma t}
\end{aligned}
$$

$$
\left.\begin{array}{rl}
\text { ここで } & \\
\bar{e}_{0}= & \frac{\sinh \lambda_{0}-\sinh \bar{\lambda}_{0}}{\lambda_{0} \cosh \lambda_{0}}, \bar{e}_{n}=\frac{\sin \lambda_{n}-\sin \bar{\lambda}_{n}}{\lambda_{n} \cos \lambda_{n}}, \\
\overline{f_{s}{ }^{(1)}}= & \frac{2 I_{1}(\bar{s} a)}{\bar{s} a I_{0}(\bar{s} a)}, \overline{f_{s}^{(2)}}=\frac{4 I_{2}(\bar{s} a)}{\bar{s} a I_{1}(\bar{s} a)} \\
\bar{g}_{0}= & \frac{1}{\lambda_{0} \cosh \lambda_{0}}\left\{\left(q \lambda_{0} \sinh \bar{\lambda}_{0}+\cosh \bar{\lambda}_{0}-\cosh \lambda_{0}\right) / \lambda_{0}\right. \\
& \left.-\left(\sinh \lambda_{0}-\sinh \bar{\lambda}_{0}\right) \bar{z}_{0} / h\right\} \\
\bar{g}_{n}= & \frac{1}{\lambda_{n} \cos \lambda_{n}}\left\{\left(q \lambda_{n} \sin \bar{\lambda}_{n}-\cos \bar{\lambda}_{n}+\cos \lambda_{n}\right) / \lambda_{n}\right. \\
& \left.-\left(\sin \lambda_{n}-\sin \bar{\lambda}_{n}\right) \bar{z}_{0} / h\right\} \\
\lambda_{0}= & k h, \bar{\lambda}_{0}=\bar{q} \lambda_{0}, \lambda_{n}=k_{n} h, \bar{\lambda}_{n}=\bar{q} \lambda_{n}, \quad r=\sigma^{2} h / g
\end{array}\right\}
$$

式（2）と（27）を式（25）に代入し整理すると， $\boldsymbol{\xi}$, $\eta, \omega$ は速度ポテンシャルの定数項により次のように表わ される。

$$
\begin{aligned}
& \xi \sigma a=-i \alpha_{0} \alpha_{1}\left[e_{0}{ }^{\prime}\left(A_{10}+B_{10}\right)+\sum_{n=1}^{\infty} e_{n}{ }^{\prime} C_{1 n}\right. \\
& \left.-\frac{1}{4} \alpha_{3}{ }^{\prime}\left(\frac{a}{h}\right)^{2}\left(D_{10}+\sum_{s=1}^{\infty} \overline{f_{s}^{(2)}} D_{1 s}\right)\right] . . \\
& \eta \sigma h=i \alpha_{2}\left[D_{00}+\sum_{s=1}^{\infty} \overline{f_{s}^{(1)}} D_{0 s}\right] \\
& \omega \sigma a^{2}=i \alpha_{0} \alpha_{3}\left[g_{0}{ }^{\prime}\left(A_{10}+B_{10}\right)+\sum_{n=1}^{\infty} g_{n}{ }^{\prime} C_{1 n}\right. \\
& \left.+\frac{1}{4}\left(\frac{a}{h}\right)^{2}\left(D_{10}+\sum_{s=1}^{\infty} \overline{f_{s}^{(2)}} D_{1 s}\right)\right] \\
& \alpha_{0}=1 /\left(1-4 \alpha_{1} \alpha_{3} k_{\theta x} k_{x \theta}\right), \quad \alpha_{1}=1 /\left(\mu q-2 k_{x x}\right), \\
& \alpha_{3}{ }^{\prime}=2 \alpha_{3} k_{x \theta} \\
& \alpha_{2}=1 /\left\{\mu q-\frac{1}{r}-2 k_{z z}+4 \frac{a}{h} \sum_{s=1}^{\infty} \cdot\right. \\
& \text { - } \left.\frac{\operatorname{coth}\left(\bar{q} \lambda_{0 s} h / a\right)}{\lambda_{0 s}{ }^{3}}\right\} \\
& \alpha_{3}=4\left(\frac{h}{a}\right) /\left\{\nu^{2} \mu q\left(1+\frac{1}{3}(\mu q h / a)^{2}\right)-\frac{1}{r}\right. \\
& +\frac{2}{r} \frac{a}{h}\left(\frac{q h}{a}+2 \frac{\bar{z}_{0}}{a}\right)-8 k_{\theta \theta} \\
& \left.+8 \frac{a}{h} \sum_{s=1}^{\infty} \frac{\operatorname{coth}\left(\bar{q} \lambda_{1 s} h / a\right)}{\lambda_{1 s}{ }^{3}}\right\} \\
& e_{0}{ }^{\prime}=\bar{e}_{0}-\alpha_{3}{ }^{\prime} \bar{g}_{0}, e_{n}{ }^{\prime}=\bar{e}_{n}-\alpha_{3}{ }^{\prime} \bar{g}_{n}, \\
& g_{0}{ }^{\prime}=\bar{g}_{0}-2 \alpha_{1} k_{\theta x} \bar{e}_{0}, g_{n}{ }^{\prime}=\bar{g}_{n}-2 \alpha_{1} k_{\theta x} \bar{e}_{n} \\
& k_{x x}=K_{x x} / \rho g \pi a^{2} \gamma, k_{z z}=K_{z z} / \rho g \pi a^{2} \gamma \text {, } \\
& k_{x \theta}=K_{x \theta} / \rho g \pi a^{3} \gamma, k_{\theta x}=K_{\theta x} / \rho g \pi a^{3} \gamma \text {, } \\
& k_{\theta \theta}=K_{\theta \theta} / \rho g \pi a^{4} \gamma
\end{aligned}
$$

\section{（4）速度ポテンシャルの定数項の決定}

境界面 $r=a$ においては浮体側面の運動学的境界条件 式 (5) と流体域の内域と外域の間の mass flux と energy flux の連続性の条件とから次の関係式がなりたつ。

$0>z>-q h$ で $\partial \phi_{1} / \partial r=i \sigma\left\{\xi+\left(\bar{z}_{0}-z\right) \omega\right\} \cos \theta$ 
$-q h>z>-h$ で $\partial \phi_{1} / \partial r=\partial \phi_{2} / \partial r ; \phi_{2}=\phi_{1}$

上の関係式に式 (9)，(22) を代入すると次式を得る。

$$
\begin{aligned}
& \sum_{m=0}^{\infty}\left\{\left(A_{m 0} \frac{J_{m}{ }^{\prime}(k a)}{J_{m}(k a)}+B_{m 0} \frac{H_{m}{ }^{(2)}{ }^{\prime}(k a)}{H_{m}{ }^{(2)}(k a)}\right) \cdot\right. \\
& \quad \cdot \frac{\cosh k(z+h)}{\cosh k h}+\sum_{n=1}^{\infty} C_{m n} \frac{K_{m}{ }^{\prime}\left(k_{n} a\right)}{K_{m}\left(k_{n} a\right)} \cdot \\
& \left.\quad \cdot \frac{k_{n} \cos k_{n}(z+h)}{k \cos k_{n} h}\right\} \cos m \theta \\
& =i \frac{\sigma}{k}\left\{\xi+\left(\bar{z}_{0}-z\right) \omega\right\} \cos \theta \quad(0>z>-q h) \\
& =\sum_{m=0}^{\infty} \frac{1}{a k}\left\{m D_{m 0}+\sum_{s=1}^{\infty} D_{m s} \frac{\bar{s} a I_{m}{ }^{\prime}(\bar{s} a)}{I_{m}(\bar{s} a)} \cdot\right. \\
& \cdot \cos \bar{s}(z+q h)\} \cos m \theta+2 i \sum_{s=1}^{\infty}\left\{\frac{\eta \sigma h}{\lambda_{0}} \cdot\right. \\
& \cdot \frac{J_{0}{ }^{\prime}\left(\lambda_{0 s}\right)}{\lambda_{0 s} J_{1}\left(\lambda_{0 s}\right)} \cdot \frac{\cosh \left(\lambda_{0 s}(z+h) / a\right)}{\sinh \left(\bar{q} \lambda_{0 s} h / a\right)}+\frac{\omega \sigma a^{2}}{k a} \cdot \\
& \left.\cdot \frac{J_{1}^{\prime}\left(\lambda_{1 s}\right)}{\lambda_{1 s} J_{2}\left(\lambda_{1 s}\right)} \cdot \frac{\cosh \left(\lambda_{1 s}(z+h) / a\right)}{\sinh \left(\bar{q} \lambda_{1 s} h / a\right)} \cos \theta\right\} \\
& \quad(-q h>z>-h) \cdot \cdot(35)
\end{aligned}
$$$$
\sum_{m=0}^{\infty}\left\{D_{m 0}+\sum_{s=1}^{\infty} D_{m s} \cos \bar{s}(z+q h)\right\} \cos m \theta
$$$$
=\sum_{m=0}^{\infty}\left\{\left(A_{m 0}+B_{m 0}\right) \frac{\cosh k(z+h)}{\cosh k h}\right.
$$$$
\left.+\sum_{n=1}^{\infty} C_{m n} \frac{\cos k_{n}(z+h)}{\cos k_{n} h}\right\} \cos m \theta
$$$$
(-q h>z>-h) \cdot \cdot(36)
$$

関数系 $\cosh k(z+h), \quad \cos k_{n}(z+h), \quad(n=1,2,3 \cdots)$ は $0>z>-h$ で, また $\cos \bar{s}(z+q h),(s=0,1,2, \cdots)$ は $-q h>z>-h$ で完全直交系であるから, 式 (35) の 各項に $\cosh k(z+h)$ または $\cos k_{n}(z+h)$ を乗じて $z=$ 一 $h$ から $z=0$ までの積分を行ない, また式 (36) の各 項には $\cos \bar{s}(z+q h)$ を乗じて $z=-h$ から $z=-q h$ ま での積分を行ならと, 式 (35) からは次の関係式を得 る。

$$
\begin{aligned}
& \sum_{m=0}^{\infty}\left(a_{m}{ }^{(0)} A_{m 0}+b_{m}{ }^{(0)} B_{m 0}\right) \cos m \theta \\
& =i v^{(0)} \eta \sigma h+i\left(h^{(0)} \xi \sigma a+r^{(0)} \omega \sigma a^{2}\right) \cos \theta \\
& \quad+\sum_{m=0}^{\infty}\left(d_{m 0}{ }^{(0)} D_{m 0}+\sum_{s=1}^{\infty} d_{m s^{(0)}} D_{m s}\right) \cos m \theta \\
& \ldots \ldots \ldots \ldots \ldots \ldots(37) \\
& \sum_{m=0}^{\infty} b_{m}{ }^{(n)} C_{m n} \cos m \theta \\
& =i v^{(n)} \eta \sigma h+i\left(h^{(n)} \xi \sigma a+r^{(n)} \omega \sigma a^{2}\right) \cos \theta \\
& \quad+\sum_{m=0}^{\infty}\left(d_{m 0}{ }^{(n)} D_{m 0}+\sum_{s=1}^{\infty} d_{m s}{ }^{(n)} D_{m s}\right) \cos m \theta
\end{aligned}
$$

式 (36) からは次式を得る。

$$
\begin{gathered}
\sum_{m=0}^{\infty} D_{m s} \cos m \theta=\varepsilon_{s} \sum_{m=0}^{\infty}\left\{e_{s}{ }^{(0)}\left(A_{m 0}+B_{m 0}\right)\right. \\
\left.+\sum_{n=1}^{\infty} e_{s}{ }^{(n)} C_{m n}\right\} \cos m \theta \ldots \ldots \ldots \ldots \ldots \ldots \ldots \ldots \ldots \ldots \ldots \ldots \ldots
\end{gathered}
$$

ここで

$N_{0}=\frac{1}{2}\left(1+\frac{2 \lambda_{0}}{\sinh 2 \lambda_{0}}\right), N_{n}=\frac{1}{2}\left(1+\frac{2 \lambda_{n}}{\sin 2 \lambda_{n}}\right), a_{m}{ }^{(0)}=N_{0} \sinh \lambda_{0} J_{m}{ }^{\prime}(k a) / J_{m}(k a)$

$b_{m}{ }^{(0)}=N_{0} \sinh \lambda_{0} \cdot H_{m}^{\left({ }^{(2)}\right.}(k a) / H_{m}{ }^{(2)}(k a), b_{m}{ }^{(n)}=N_{n} \sin \lambda_{n} \cdot K_{m}{ }^{\prime}\left(k_{n} a\right) / K_{m}\left(k_{n} a\right)$

$h^{(0)}=\left(\sinh \lambda_{0}-\sinh \bar{\lambda}_{0}\right) h / a \lambda_{0}, h^{(n)}=\left(\sin \lambda_{n}-\sin \bar{\lambda}_{n}\right) h / a \lambda_{n}$

$v^{(0)}=-2 \frac{a}{h} \sum_{s=1}^{\infty} \frac{1}{\lambda_{0 s}} \cdot \frac{k a \sinh \bar{q} \lambda_{0} \operatorname{coth}\left(\bar{q} \lambda_{0 s} h / a\right)-\lambda_{0 s} \cosh \bar{q} \lambda_{0}}{(k a)^{2}-\left(\lambda_{0 s}\right)^{2}}$

$v^{(n)}=-2 \frac{a}{h} \sum_{s=1}^{\infty} \frac{1}{\lambda_{0 s}} \cdot \frac{k_{n} a \sin \bar{q} \lambda_{n} \operatorname{coth}\left(\bar{q} \lambda_{0 s} h / a\right)+\lambda_{0 s} \cos \bar{q} \lambda_{n}}{\left(k_{n} a\right)^{2}+\left(\lambda_{0 s}\right)^{2}}$

$r^{(0)}=\left(\frac{h}{a}\right)^{2}\left\{\left(\sinh \lambda_{0}-\sinh \bar{\lambda}_{0}\right) \bar{z}_{0} / h \lambda_{0}-\left(q \lambda_{0} \sinh \bar{\lambda}_{0}+\cosh \bar{\lambda}_{0}-\cosh \lambda_{0}\right) / \lambda_{0}{ }^{2}\right\}$

$+2 \sum_{s=1}^{\infty} \frac{J_{1}^{\prime}\left(\lambda_{1 s}\right)}{\lambda_{1 s} J_{2}\left(\lambda_{1 s}\right)} \cdot \frac{k a \sinh \bar{q} \lambda_{0} \operatorname{coth}\left(\bar{q} \lambda_{1 s} h / a\right)-\lambda_{1 s} \cosh \bar{q} \lambda_{0}}{(k a)^{2}-\left(\lambda_{1 s}\right)^{2}}$

$r^{(n)}=\left(\frac{h}{a}\right)^{2}\left\{\left(\sin \lambda_{n}-\sin \bar{\lambda}_{n}\right) \bar{z}_{0} / h \lambda_{n}-\left(q \lambda_{n} \sin \bar{\lambda}_{n}-\cos \bar{\lambda}_{n}+\cos \lambda_{n}\right) / \lambda_{n}^{2}\right\}$

$+2 \sum_{s=1}^{\infty} \frac{J_{1}^{\prime}\left(\lambda_{1 s}\right)}{\lambda_{1 s} J_{2}\left(\lambda_{1 s}\right)} \cdot \frac{k_{n} a \sin \bar{q} \lambda_{n} \operatorname{coth}\left(\bar{q} \lambda_{1 s} h / a\right)+\lambda_{1 s} \cos \bar{q} \lambda_{n}}{\left(k_{n} a\right)^{2}+\left(\lambda_{1 s}\right)^{2}}$

$d_{m 0}{ }^{(0)}=\frac{h}{a} \cdot \frac{\sinh \bar{\lambda}_{0}}{\lambda_{0}} \cdot m, d_{m s}{ }^{(0)}=\frac{h}{a} \cdot \frac{\sinh \bar{\lambda}_{0}}{\lambda_{0}} \cdot \frac{\bar{s} a I_{m}{ }^{\prime}(\bar{s} a)}{I_{m}(\bar{s} a)} \cdot \frac{1}{1+\left(s \pi / \bar{\lambda}_{0}\right)^{2}}$

$d_{m 0}{ }^{(n)}=\frac{h}{a} \cdot \frac{\sin \bar{\lambda}_{n}}{\lambda_{n}} \cdot m, d_{m s}{ }^{(n)}=\frac{h}{a} \cdot \frac{\sin \bar{\lambda}_{n}}{\lambda_{n}} \cdot \frac{\bar{s} a I_{m}{ }^{\prime}(\bar{s} a)}{I_{m}(\bar{s} a)} \cdot \frac{1}{1-\left(s \pi / \bar{\lambda}_{n}\right)^{2}}$

$e_{s}{ }^{(0)}=\frac{\sinh \bar{\lambda}_{0}}{\bar{\lambda}_{0} \cosh \lambda_{0}} \cdot \frac{1}{1+\left(s \pi / \bar{\lambda}_{0}\right)^{2}}, e_{s}^{(n)}=\frac{\sin \bar{\lambda}_{n}}{\bar{\lambda}_{n} \cos \lambda_{n}} \cdot \frac{1}{1-\left(s \pi / \bar{\lambda}_{n}\right)^{2}}$

式 (37)～(39) に式 (29)～(31) を代入し， $m$ の等しい項を等置すると，速度ポテンシャルの係数を決定すべき 連立方程式として $m$ のおのおのの值に対して次の諸式を得る。

$m=0$ に対して

$$
b_{0}{ }^{(0)} \frac{B_{00}}{A_{00}}+\alpha_{2} v^{(0)} \frac{D_{00}}{A_{00}}+\sum_{s=1}^{\infty}\left(\alpha_{2} v^{(0)} \overline{f_{s}^{(1)}}-d_{0 s^{(0)}}\right) \frac{D_{0 s}}{A_{00}}=-a_{0}{ }^{(0)}
$$




$$
\begin{aligned}
& b_{0}{ }^{(n)} \frac{C_{0 n}}{A_{00}}+\alpha_{2} v^{(n)} \frac{D_{00}}{A_{00}}+\sum_{s=1}^{\infty}\left(\alpha_{2} v^{(n)} \overline{f_{s}^{(1)}}-d_{0 s}^{(n)}\right) \frac{D_{0 s}}{A_{00}}=0, \quad(n=1,2,3 \cdots) \\
& e_{s}{ }^{(0)} \frac{B_{00}}{A_{00}}+\sum_{p=1}^{\infty} e_{s}^{(p)} \frac{C_{0 p}}{A_{00}}-\frac{1}{\varepsilon_{s}} \frac{D_{0 s}}{A_{00}}=-e_{s}^{(0)},(s=0,1,2,3 \cdots)
\end{aligned}
$$

$m=1$ に対して

$$
\begin{aligned}
& \left\{\left(b_{1}{ }^{(0)}-\alpha_{0}\left(\alpha_{1} e_{0} h^{(0)}-\alpha_{3} g_{0}{ }^{(0)}\right)\right\} \frac{B_{10}}{A_{10}}-\alpha_{0} \sum_{p=1}^{\infty}\left(\alpha_{1} e_{p} h^{(0)}-\alpha_{3} g_{p}{ }^{\prime} r^{(0)}\right) \frac{C_{1 p}}{A_{10}}\right. \\
& -\left\{d_{10}{ }^{(0)}-\frac{1}{4} \alpha_{0}\left(\frac{a}{h}\right)^{2}\left(\alpha_{1} \alpha_{3}{ }^{\prime} h^{(0)}+\alpha_{3} r^{(0)}\right)\right\} \frac{D_{10}}{A_{10}}-\sum_{s=1}^{\infty}\left\{d_{1 s}{ }^{(0)}-\frac{1}{4} \alpha_{0}\left(\frac{a}{h}\right)^{2}\left(\alpha_{1} \alpha_{3}{ }^{\prime} h^{(0)}\right.\right. \\
& \left.\left.+\alpha_{3} r^{(0)}\right) \overline{f_{s}^{(2)}}\right\} \frac{D_{1 s}}{A_{10}}=-\left\{a_{1}{ }^{(0)}-\alpha_{0}\left(\alpha_{1} e_{0} h^{(0)}-\alpha_{3} g_{0}{ }^{\prime} r^{(0)}\right)\right\} \\
& \alpha_{0}\left(\alpha_{1} e_{0}^{\prime} h^{(n)}-\alpha_{3} g_{0}{ }^{\prime} r^{(n)}\right) \frac{B_{10}}{A_{10}}-b_{1}{ }^{(n)} \frac{C_{1 n}}{A_{10}}+\alpha_{0} \sum_{p=1}^{\infty}\left(\alpha_{1} e_{p} h^{(n)}-\alpha_{3} g_{p}{ }^{\prime} r^{(n)}\right) \frac{C_{1 p}}{A_{10}} \\
& +\left\{d_{10}{ }^{(n)}-\frac{1}{4} \alpha_{0}\left(\frac{a}{h}\right)^{2}\left(\alpha_{1} \alpha_{3}{ }^{\prime} h^{(n)}+\alpha_{3} r^{(n)}\right)\right\} \frac{D_{10}}{A_{10}}+\sum_{s=1}^{\infty}\left\{d_{1 s}{ }^{(n)}-\frac{1}{4} \alpha_{0}\left(\frac{a}{h}\right)^{2} .\right. \\
& \left.\cdot\left(\alpha_{1} \alpha_{3}{ }^{\prime} h^{(n)}+\alpha_{3} r^{(n)}\right) \overline{f_{s}^{(2)}}\right\} \frac{D_{1 s}}{A_{10}}=-\alpha_{0}\left(\alpha_{1} e_{0}{ }^{\prime} h^{(n)}-\alpha_{3} g_{0}{ }^{\prime} r^{(n)}\right), \quad(n=1,2,3 \cdots) \\
& e_{s}{ }^{(0)} \frac{B_{10}}{A_{10}}+\sum_{p=1}^{\infty} e_{s}{ }^{(p)} \frac{C_{1 p}}{A_{10}}-\frac{1}{\varepsilon_{s}} \frac{D_{1 s}}{A_{10}}=-e_{s}^{(0)} \quad(s=0,1,2 \cdots)
\end{aligned}
$$

$m \geqq 2$ に対して

$$
\begin{aligned}
& b_{m}{ }^{(0)} \frac{B_{m 0}}{A_{m 0}}-d_{m 0}{ }^{(0)} \frac{D_{m 0}}{A_{m 0}}-\sum_{s=1}^{\infty} d_{m s}{ }^{(0)} \frac{D_{m s}}{A_{m 0}}=-a_{m}{ }^{(0)} \\
& b_{m}{ }^{(n)} \frac{C_{m n}}{A_{m 0}}-d_{m 0}{ }^{(n)} \frac{D_{m 0}}{A_{m 0}}-\sum_{s=1}^{\infty} d_{m s}{ }^{(n)} \frac{D_{m s}}{A_{m 0}}=0 \quad(n=1,2,3 \cdots) \\
& e_{s}{ }^{(0)} \frac{B_{m 0}}{A_{m 0}}+\sum_{p=1}^{\infty} e_{s}{ }^{(p)} \frac{C_{m p}}{A_{m 0}}-\frac{1}{\varepsilon_{s}} \frac{D_{m s}}{A_{m 0}}=-e_{s}{ }^{(0)} \quad(s=0,1,2,3 \cdots)
\end{aligned}
$$

上の各式を解いて $m=0,1,2, \cdots$ に対する $B_{00} / A_{00}, C_{0 n} / A_{00}, D_{00} / A_{00}, D_{0 s} / A_{00} ; B_{10} / A_{10}, C_{1 n} / A_{10}, D_{10} / A_{10}$, $D_{1 s} / A_{10} ; B_{m 0} / A_{m 0}, C_{m n} / A_{m 0}, D_{m 0} / A_{m 0}, D_{m s} / A_{m 0}$ が決まり, 式 (13) により, 入射波 $\zeta_{i}=\zeta_{0} \cos (k x+\sigma t)$ に対し て速度ポテンシャルが確定する。

\section{（5）水面波形と圧力および浮体運動}

（i）外域の水面波形は式 (11) を用いて次式の実数部分で表わされる。

$$
\zeta(r, \theta ; t)=\zeta_{0} \sum_{m=0}^{\infty} i^{m} \varepsilon_{m} J_{m}(k a)\left\{\frac{J_{m}(k r)}{J_{m}(k a)}+\frac{B_{m 0}}{A_{m 0}} \cdot \frac{H_{m}^{(2)}(k r)}{H_{m}^{(2)}(k a)}+\sum_{n=1}^{\infty} \frac{C_{m n}}{A_{m 0}} \frac{K_{m}\left(k_{n} r\right)}{K_{m}\left(k_{n} a\right)}\right\} \cos m \theta \cdot e^{i \sigma t} .
$$

（ii） 浮体に作用する水平と鉛直方向の流体圧力の合力 $P_{H}$ と $P_{V}$ および重心に関する流体圧力の全モーメント $T$ は式 (13) と（27）から次のよらである。

$$
\begin{aligned}
& \frac{P_{H}}{2 \rho g \zeta_{0} \pi a h}=i J_{1}(k a)\left[\bar{e}_{0}\left(1+\frac{B_{10}}{A_{10}}\right)+\sum_{n=1}^{\infty} \bar{e}_{n} \cdot \frac{C_{1 n}}{A_{10}}\right] e^{i \sigma t} \\
& \frac{P_{V}}{\rho g \zeta_{0} \pi a^{2}}=J_{0}(k a)\left[1+\alpha_{2}\left\{\frac{1}{r}-4 \frac{a}{h} \sum_{s=1}^{\infty} \frac{1}{\lambda_{0 s}{ }^{3} \sinh \left(\bar{q} \lambda_{0 s} h / a\right)}\right\}\right]\left(\frac{D_{00}}{A_{00}}+\sum_{s=1}^{\infty} \overline{f_{s}^{(1)}} \frac{D_{0 s}}{A_{00}}\right) e^{i \sigma t} \\
& \frac{T}{2 \rho g \zeta_{0} \pi a h^{2}}=i J_{1}(k a)\left[\left(\bar{g}_{0}-\bar{M} g_{0}{ }^{\prime}\right)\left(1-\frac{B_{10}}{A_{10}}\right)+\sum_{n=1}^{\infty}\left(\bar{g}_{n}-\bar{M} g_{n}{ }^{\prime}\right) \frac{C_{1 n}}{A_{10}}+\frac{1-\bar{M}}{4}\left(\frac{a}{h}\right)^{2}\left(\frac{D_{10}}{A_{10}}+\sum_{s=1}^{\infty} \overline{f_{s}^{(2)}} \frac{D_{1 s}}{A_{10}}\right)\right] \text {. }
\end{aligned}
$$

$$
\cdot e^{i o t}
$$

ここで, $\bar{M}=2 \alpha_{0} \alpha_{3}\left(\frac{a}{h}\right)^{2}\left\{\sum_{s=0}^{\infty} \frac{\operatorname{coth}\left(\bar{q} \lambda_{1 s} h / a\right)}{\lambda_{1 s}{ }^{3}}-\frac{1}{8} \cdot \frac{h}{a} \cdot \frac{1}{r}+\frac{q}{r}\left(\frac{h}{a}\right)^{2}\left(\frac{\bar{z}_{0}}{a}+\frac{q h}{2 a}\right)\right\}$

（iii）浮体重心の水平と鉛直変位および回転角は式 (29) （31）から次式の実数部分で表わされる。

$$
\begin{aligned}
& \frac{x_{0}}{\zeta_{0}}=2 i \frac{h}{a} \frac{\alpha_{0} \alpha_{1}}{\gamma} J_{1}(k a)\left[e_{0}^{\prime}\left(1+\frac{B_{10}}{A_{10}}\right)+\sum_{n=1}^{\infty} e_{n}^{\prime} \frac{C_{1 n}}{A_{10}}-\frac{1}{4} \alpha_{3}{ }^{\prime}\left(\frac{a}{h}\right)^{2}\left(\frac{D_{10}}{A_{10}}+\sum_{s=1}^{\infty} \overline{f_{s}{ }^{(2)}} \frac{D_{1 s}}{A_{10}}\right)\right] e^{i \sigma t} \\
& \frac{z_{0}-\bar{z}_{0}}{\zeta_{0}}=-\alpha_{2} \frac{1}{r} J_{0}(k a)\left[\frac{D_{00}}{A_{00}}+\sum_{s=1}^{\infty} \overline{f_{s}^{(1)}} \frac{D_{0 s}}{A_{00}}\right] e^{i \sigma t} \\
& \frac{\delta a}{\zeta_{0}}=-2 i \frac{h}{a} \cdot \frac{\alpha_{0} \alpha_{3}}{r} J_{1}(k a)\left[g_{0}\left(1+\frac{B_{10}}{A_{10}}\right)+\sum_{n=1}^{\infty} g_{n}{ }^{\prime} \frac{C_{1 n}}{A_{10}}+\frac{1}{4}\left(\frac{a}{h}\right)^{2}\left(\frac{D_{10}}{A_{10}}+\sum_{s=1}^{\infty} \frac{f_{s}^{(2)}}{A_{10}}\right)\right] e^{i \sigma t}
\end{aligned}
$$




\section{（6）繫留索に作用する引張りカ}

浮体の変位と回転に対する繋留索の反力 $K_{x x}, K_{z z} \cdots$ 等は索の性質により異なるが，ここでは単純な引張りば ねと仮定したときを考えると，Fig. 2 に示すように索

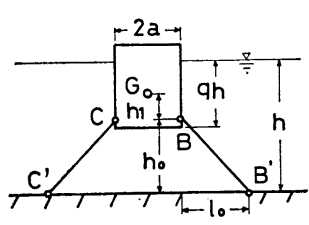

(a) Open Spring Mooring

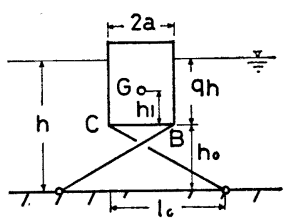

(b) Cross Spring Mooring
Fig. 2

の着力点を重心 $G$ から $h_{1}$ だけ下の点 $B, C$ とすれば, ばね定数 (単位の伸びを生ずる引張り力) $K$ を用いると Fig. 2 (a) のような open type の繋留の場合は $k_{x x}$, $k_{z z} \cdots$ 等は次のようになる。

$$
\begin{aligned}
& k_{x x}=\frac{1}{r} \cdot \frac{1}{1+\left(h_{0} / l_{0}\right)^{2}} \cdot \frac{K}{\rho g \pi a^{2}} \\
& k_{z z}=\frac{1}{r} \cdot \frac{\left(h_{0} / l_{0}\right)^{2}}{1+\left(h_{0} / l_{0}\right)^{2}} \cdot \frac{K}{\rho g \pi a^{2}} \\
& k_{x \theta}=k_{\theta x}=\frac{1}{r} \cdot \frac{h_{1} / a-h_{0} / l_{0}}{1+\left(h_{0} / l_{0}\right)^{2}} \cdot \frac{K}{\rho g \pi a^{2}} \\
& k_{\theta \theta}=\frac{1}{r} \cdot \frac{\left(h_{1} / a-h_{0} / l_{0}\right)^{2}}{1+\left(h_{0} / l_{0}\right)^{2}} \cdot \frac{K}{\rho g \pi a^{2}}
\end{aligned}
$$

Fig. 2 (b) のような cross type の場合は $k_{x x}, k_{z z}$ は 上式と同じであるが，その他は次のようである。

$$
\left.\begin{array}{l}
k_{x \theta}=k_{\theta x}=\frac{1}{r} \cdot \frac{h_{1} / a+h_{0} / l_{0}}{1+\left(h_{0} / l_{0}\right)^{2}} \cdot \frac{K}{\rho g \pi a^{2}} \\
k_{\theta \theta}=\frac{1}{r} \cdot \frac{\left(h_{1} / a+h_{0} / l_{0}\right)^{2}}{1+\left(h_{0} / l_{0}\right)^{2}} \cdot \frac{K}{\rho g \pi a^{2}}
\end{array}\right\}
$$

円柱の運動による点 $B$ の静止位置からの変位を $\left(x_{0}\right)$, $\left(z_{0}\right)$ とすると,

$$
\frac{\left(x_{0}\right)}{\zeta_{0}}=\frac{x_{0}}{\zeta_{0}}+\frac{1}{2} \frac{q h}{a} \cdot \frac{\delta a}{\zeta_{0}}, \frac{\left(z_{0}\right)}{\zeta_{0}}=\frac{\delta a}{\zeta_{0}}+\frac{z_{0}-\bar{z}_{0}}{\zeta_{0}}
$$

の関係にあるから, 浮体運動により索に生ずる繋留力 $F$ は次式で与えられる。

$$
F / \zeta_{0} K=\left\{\frac{\left(x_{0}\right)}{\zeta_{0}} \mp \frac{h_{0}}{l_{0}} \cdot \frac{\left(z_{0}\right)}{\zeta_{0}}\right\} / \sqrt{1+\left(h_{0} / l_{0}\right)^{2}}
$$

上式でーは Fig. 2 (a)，＋は Fig. 2 (b) の場合 に対応する。

\section{（7）円柱浮体の自由運動}

上述の場合で繋留索を省略すると自由運動を表わす。 このときは式 (32) において

$$
\left.\begin{array}{l}
\mu=1, k_{x x}=k_{z z}=k_{x \theta}=k_{\theta x}=k_{\theta \theta}=0, \alpha_{0}=1, \alpha_{3}{ }^{\prime}=0 \\
\alpha_{1}=1 / q, e_{0}^{\prime}=\bar{e}_{0}, e_{n}^{\prime}=\bar{e}_{n}, g_{0}{ }^{\prime}=\bar{g}_{0}, g_{n}{ }^{\prime}=\bar{g}_{n}
\end{array}\right\}
$$

とすればよい。式 (29)〜 (31) は次のようになる。

$$
\begin{aligned}
\xi \sigma a= & -i \alpha_{1}\left[\bar{e}_{0}\left(A_{10}+B_{10}\right)+\sum_{n=1}^{\infty} \bar{e}_{n} C_{1 n}\right] \ldots . . \\
\eta \sigma h= & i \alpha_{2}\left[D_{00}+\sum_{s=1}^{\infty} \overline{f_{s}^{(1)}} D_{0 s}\right] \ldots \ldots \ldots \ldots \ldots . . . \\
\omega \sigma a^{2}= & i \alpha_{3}\left[\bar{g}_{0}\left(A_{10}+B_{10}\right)+\sum_{n=1}^{\infty} \bar{g}_{n} C_{1 n}\right. \\
& \left.+\frac{1}{4}\left(\frac{a}{h}\right)^{2}\left(D_{10}+\sum_{s=1}^{\infty} \overline{f_{s}^{(2)}} D_{1 s}\right)\right] \ldots \ldots
\end{aligned}
$$

速度ポテンシャルの係数を決める連立方程式は $m=1$ に対する式 (42) だけが次のように簡単になる。

$$
\begin{aligned}
&\left(b_{1}{ }^{(0)}-\alpha_{1} \bar{e}_{0} h^{(0)}+\alpha_{3} \bar{g}_{0} r^{(0)}\right) \frac{B_{10}}{A_{10}}-\sum_{p=1}^{\infty}\left(\alpha_{1} \bar{e}_{p} h^{(0)}\right.\left.-\alpha_{3} \bar{g}_{p} r^{(0)}\right) \frac{C_{1 p}}{A_{10}}-\left\{d_{10}{ }^{(0)}-\frac{1}{4}\left(\frac{a}{h}\right)^{2} \alpha_{3} r^{(0)}\right\} \cdot \\
& \cdot \frac{D_{10}}{A_{10}}-\sum_{s=1}^{\infty}\left\{d_{1 s}{ }^{(0)}-\frac{1}{4}\left(\frac{a}{h}\right)^{2} \alpha_{3} r^{(0)} \overline{f_{s}^{(2)}}\right\} \frac{D_{1 s}}{A_{10}} \\
&=-\left(a_{1}{ }^{(0)}-\alpha_{1} \bar{e}_{0} h^{(0)}+\alpha_{3} \bar{g}_{0} r^{(0)}\right) \\
&\left(\alpha_{1} \bar{e}_{0} h^{(n)}-\alpha_{3} \bar{g}_{0} r^{(n)}\right) \frac{B_{10}}{A_{10}}-b_{1}{ }^{(n)} \frac{C_{1 n}}{A_{10}}+\sum_{p=1}^{\infty} \cdot \\
& \cdot\left(\alpha_{1} \bar{e}_{p} h^{(n)}-\alpha_{3} \bar{g}_{p} r^{(n)}\right) \frac{C_{1 p}}{A_{10}}+\left\{d_{10}(n)-\frac{1}{4} \cdot\right. \\
&\left.\cdot\left(\frac{a}{h}\right)^{2} \alpha_{3} r^{(n)}\right\} \frac{D_{10}}{A_{10}}+\sum_{s=1}^{\infty}\left\{d_{1 s}{ }^{(n)}-\frac{1}{4}\left(\frac{a}{h}\right)^{2} .\right. \\
&\left.\cdot \alpha_{3} r^{(n)} \overline{f_{s}(2)}\right\} \frac{D_{1 s}}{A_{10}}=-\left(\alpha_{1} \bar{e}_{0} h^{(n)}-\alpha_{3} \bar{g}_{0} r^{(n)}\right), \\
& \quad(n=1,2,3 \cdots) \\
& e_{s}{ }^{(0)} \frac{B_{10}}{A_{10}}+\sum_{n=1}^{\infty} e_{s}{ }^{(n)} \frac{C_{1 n}}{A_{10}}-\frac{1}{\varepsilon_{s}} \cdot \frac{D_{1 s}}{A_{10}} \\
&=-e_{s}{ }^{(0)},(s=0,1,2 \cdots)
\end{aligned}
$$

\section{3. 円柱の強制運動による発生波と圧カ}

上述の計算法は与えられた入射波による円柱の運動を 求めるものであるが，反対に円柱に強制運動を与えたと きに発生する波や, 円柱に作用する流体圧力, したがっ ていわゆる付加質量や減衰力を算定するにも応用され る。ここでは円柱に上下摇 (heaving), 左右摇 (swaying) および横摇（rolling）を与えたときの諸量を求める。

\section{（1） heaving motion による波の発生}

円柱が $\eta=\eta_{0} \cos \sigma t$ で表わされる上下摇を行なう場合 は，境界条件は式 (5)，（6）において $\xi=\omega=0$ とおけ ばよく，流体運動は $\theta$ には関係せず，また入射波はない から, 外域の速度ポテンシャル $\phi_{1}(r, \theta, z)$ は式 $(9)$ に おいて $m=0, A_{00}=0$, 内域の速度ポテンシャル $\phi_{2}(r, \theta$, z) は式 (22) で $m=\omega=0$ とおいて表わされる。したが って heaving motion に対する速度ポテンシャルの係数 を決定する連立方程式は式 (37) (39) で $\xi=\omega=0$ とお き $m=0$ の場合のみを取り, 既知量 $\eta_{0}$ に対して次の形 
となる。

$$
\begin{aligned}
& \left(b_{0}{ }^{(0)}-2 \sum_{s=1}^{\infty} d_{0 s}{ }^{(0)} e_{s}{ }^{(0)}\right) \frac{B_{00}}{\eta_{0} \sigma h} \\
& -2 \sum_{p=1}^{\infty} \sum_{s=1}^{\infty} d_{0 s}{ }^{(0)} e_{s}^{(p)} \frac{C_{0 p}}{\eta_{0} \sigma h}=i v^{(0)} \\
& -2 \sum_{s=1}^{\infty} d_{0 s^{(n)}} e_{s}^{(0)} \frac{B_{00}}{\eta_{0} \sigma h}+b_{0}{ }^{(n)} \frac{C_{0 n}}{\eta_{0} \sigma h} \\
& \quad-2 \sum_{p=1}^{\infty} \sum_{s=1}^{\infty} d_{0 s^{(n)}} e_{s}^{(p)} \frac{C_{0 p}}{\eta_{0} \sigma h} \\
& =i v^{(n)}, \quad(n=1,2,3 \cdots)
\end{aligned}
$$

上式を解いて $B_{00} / \eta_{0} \sigma h, C_{0 n} / \eta_{0} \sigma h$ が求まると $D_{0 s} / \eta_{0} \sigma h$ は次式で与えられる。

$$
\frac{D_{0 s}}{\eta_{0} \sigma h}=\varepsilon_{s}\left(e_{s}{ }^{(0)} \frac{B_{00}}{\eta_{0} \sigma h}+\sum_{n=1}^{\infty} e_{s}^{(n)} \frac{C_{0 n}}{\eta_{0} \sigma h}\right) \cdots
$$

発生する波形は式（11）から次式の実数部分である。

$$
\begin{aligned}
\zeta(r ; t)= & -i \eta_{0} \frac{\sigma^{2} h}{g}\left(\frac{B_{00}}{\eta_{0} \sigma h} \cdot \frac{H_{0}{ }^{(2)}(k r)}{H_{0}^{(2)}(k a)}\right. \\
& \left.+\sum_{n=1}^{\infty} \frac{C_{0 n}}{\eta_{0} \sigma h} \cdot \frac{K_{0}\left(k_{n} r\right)}{K_{0}\left(k_{n} a\right)}\right) e^{i \sigma t} \ldots \ldots . .
\end{aligned}
$$

しかるに $r \rightarrow \infty$ では $K_{0}\left(k_{n} r\right) \rightarrow 0$,

$$
\begin{aligned}
& H_{0}^{(2)}(k r) \sim \sqrt{\frac{2}{\pi k r}} \cdot e^{-i(k r-\pi / 4)} \text { であるから } \\
& \frac{B_{00}}{H_{0}{ }^{(2)}(k a) \eta_{0} \sigma h}=\bar{K}_{0}+i \bar{L}_{0} \ldots \ldots \ldots \ldots \ldots \ldots \ldots \ldots \ldots \ldots \ldots
\end{aligned}
$$

とすると，

$$
\left.\begin{array}{l}
\frac{\zeta(r ; t)}{\eta_{0}} \sim \frac{\sigma^{2} h}{g} \cdot \sqrt{\frac{2}{\pi k r}} \cdot\left(\bar{K}_{0} \cos \theta+\bar{L}_{0} \sin \theta\right), \\
\Theta=k r-\sigma t-\pi / 4
\end{array}\right\}
$$

したがって，造波係数 $\bar{A}_{z}$ は

$$
\bar{A}_{z}=\sqrt{\frac{r}{a}} \cdot \frac{\zeta}{\eta_{0}}=\frac{\sigma^{2} h}{g} \cdot \sqrt{\frac{2}{\pi k a}} \cdot\left(\bar{K}_{0}{ }^{2}+\bar{L}_{0}{ }^{2}\right)^{1 / 2}
$$

また

$$
\begin{aligned}
& \frac{D_{00}}{\eta_{10} \sigma}+\sum_{s=1}^{\infty} \frac{f_{s}^{(1)}}{D_{0 s}} \frac{\bar{M}_{0}+i \bar{N}_{0},}{\eta_{0} \sigma}= \\
& 4 \frac{a}{h} \sum_{s=1}^{\infty} \frac{\operatorname{coth}\left(\bar{q} \lambda_{0 s} h / a\right)}{\lambda_{0 s}{ }^{3}}=\bar{a}
\end{aligned}
$$

とおくと, 円柱底面に作用する変動圧力は式 (27) の第 2 式から次のようになる。

$$
\frac{P_{V^{\prime}}}{\rho g \eta_{0} \pi a^{2}}=\frac{\sigma^{2} h}{g}\left\{\left(\bar{a}+\bar{N}_{0}\right) \cos \sigma t+\bar{M}_{0} \sin \sigma t\right\}
$$

上式右辺の第 1 項は円柱の加速度と同位相の質量力を 表わし，第 2 項は速度と同位相の減衰力を表わす。した がって, 付加質量係数 $K_{z}$ と減衰力係数 $N_{z}$ は上式の係 数を $\rho \pi a^{2} q h \cdot \eta_{0} \sigma^{2}$ で割って次のように求められる。

$$
K_{z}=\left(\bar{a}+\bar{N}_{0}\right) / q, N_{z}=\bar{M}_{0} / q
$$

なお，円柱底面に作用する全流体圧力は式 (27) の第 2 式で与えられ, 円柱底面の 鉛直速度 $w=-\eta_{0} \sigma \sin \sigma t$ であるから heaving motion の 1 周期 $T$ に円柱が流体 に与えるエネルギーは

$$
W=-\int_{0}^{T} P_{V}^{\prime} \eta_{0} \sigma \sin \sigma t d t=\frac{\pi}{2} \rho g a^{2} \eta_{0} \sigma \cdot \frac{\sigma^{2} h}{g} \cdot \bar{M}_{0} \cdot T
$$

で表わされ，一方流体外域を radiate する波のエネルギ 一は速度ポテンシャル $\Phi_{1}(r, \theta ; t)$ により， 1 周期につ いては

$$
\begin{aligned}
E & =\rho \int_{0}^{T} \int_{-h}^{0} \int_{-\pi}^{\pi} \frac{\partial \Phi_{1}}{\partial t} \cdot \frac{\partial \Phi_{1}}{\partial r} r d \theta d z d t \\
& =2 \rho g N_{0} \eta_{0}{ }^{2}\left(\frac{\sigma^{2} h}{g}\right)^{2} \frac{\sigma}{k}\left(\bar{K}_{0}{ }^{2}+\bar{L}_{0}{ }^{2}\right) \cdot T \cdot
\end{aligned}
$$

で計算される。したがって式 (71)，(72）を等置すると

$$
\bar{M}_{0}=\frac{4}{\pi} \cdot \frac{N_{0}}{(k a)^{2}} \cdot \frac{\sigma^{2} h}{g} \cdot\left(\bar{K}_{0}{ }^{2}+\bar{L}_{0}{ }^{2}\right)
$$

すなわち, 減衰力係数式 (70) は造波係数式 (67) に よっても求められることがわかる。上式は計算結果を検 証するに有効な式である。

\section{（2） swaying motion による波の発生}

円柱が $\xi=\xi_{0} \cos \sigma t$ で表わされる左右摇を行なら場合 は, $\phi_{1}(r, \theta, z)$ は式 (9) で $A_{m 0}=0, \phi_{2}(r, \theta, z)$ は式 (22) で $\eta=\omega=0$ とおいて表わされる。速度ポテンシャ ルを定める連立方程式は $m=0$ に対しては式 (62) で $\eta_{0} \sigma h$ の代りに $\xi_{0} \sigma a$ とおき, $v^{(0)}=v^{(n)}=0$ とおいて表 わされる。 $m=1$ に対しては次式のようである。

$$
\begin{gathered}
\left(b_{1}{ }^{(0)}-d_{10}{ }^{(0)} e_{0}{ }^{(0)}-2 \sum_{s=1}^{\infty} d_{1 s}{ }^{(0)} e_{s}{ }^{(0)}\right) \frac{B_{10}}{\xi_{0} \sigma a} \\
\quad-\sum_{p=1}^{\infty}\left(d_{10}{ }^{(0)} e_{0}{ }^{(p)}+2 \sum_{s=1}^{\infty} d_{1 s}{ }^{(0)} e_{s}{ }^{(p)}\right) \frac{C_{1 p}}{\xi_{0} \sigma a} \\
=i h^{(0)} \\
-\left(d_{10}{ }^{(n)} e_{0}{ }^{(0)}+2 \sum_{s=1}^{\infty} d_{1 s}{ }^{(n)} e_{s}{ }^{(0)}\right) \frac{B_{10}}{\xi_{0} \sigma a}+b_{1}{ }^{(n)} \frac{C_{1 n}}{\xi_{0} \sigma a} \\
\quad-\sum_{p=1}^{\infty}\left(d_{10}{ }^{(n)} e_{0}{ }^{(p)}+2 \sum_{s=1}^{\infty} d_{1 s}{ }^{(n)} e_{s}{ }^{(p)}\right) \frac{C_{1 p}}{\xi_{0} \sigma a} \\
=i h^{(n)} \quad(n=1,2,3 \cdots)
\end{gathered}
$$

$m \geqq 2$ に対しては式 (74) で添字 1 を $m$ にかえ, $h^{(0)}$ $=h^{(n)}=0$ とおけばよい。 $B_{m 0} / \xi_{0} \sigma a, C_{m n} / \xi_{0} \sigma a$ により, $D_{m s} / \xi_{0} \sigma a$ は次式で与えられる。

$$
\frac{D_{m s}}{\xi_{0} \sigma a}=\varepsilon_{s}\left(e_{s}{ }^{(0)} \frac{B_{m 0}}{\xi_{0} \sigma a}+\sum_{n=1}^{\infty} e_{s}{ }^{(n)} \frac{C_{m n}}{\xi_{0} \sigma a}\right) \cdots
$$

こらしてこの場合は $m=1$ 以外に対しては速度ポテン シャルの係数はすべて 0 となり, 式 (74), (75) から $m$ $=1$ に対する $B_{10} / \xi_{0} \sigma a, C_{1 n} / \xi_{0} \sigma a$, および $D_{1 s} / \xi_{0} \sigma a$ が決 まる。

円柱の運動により発生し radiate する波の波形は

$$
\frac{B_{10}}{H_{1}{ }^{(2)}(k a) \xi_{0} \sigma a}=\bar{K}_{1}+i \bar{L}_{1}
$$

とおくと, 次のようである。

$$
\begin{aligned}
& \frac{\zeta(r, \theta ; t)}{\xi_{0}} \sim \frac{\sigma^{2} h}{g} \frac{a}{h} \sqrt{\frac{2}{\pi k r}}\left(\bar{K}_{1} \cos \theta-\bar{L} \sin \theta\right) \text {. } \\
& \cdot \cos \theta \text {. }
\end{aligned}
$$


沖えに造波係数 $\bar{A}_{x}$ は式 (67) に対応して

$$
\bar{A}_{x}=\sqrt{\frac{r}{a}} \frac{|\xi(r, 0)|}{\xi_{0}}=\frac{\sigma^{2} h}{g} \cdot \frac{a}{h} \sqrt{\frac{2}{\pi k a}}\left(\bar{K}_{1}{ }^{2}+\bar{L}_{1}{ }^{2}\right)^{1 / 2}
$$

さらに

$$
\bar{e}_{0} \frac{B_{10}}{\xi_{0} \sigma a}+\sum_{n=1}^{\infty} \bar{e}_{n} \cdot \frac{C_{1 n}}{\xi_{0} \sigma a}=\bar{B}_{1}+i \bar{C}_{1} .
$$

とおくと, 円柱に作用する流体圧力の水平合力 $P_{H}$ は式 (27) の第 1 式から

$$
\frac{P_{H}^{\prime}}{\rho g \xi_{0} \pi a^{2}}=\frac{\sigma^{2} h}{g}\left(\bar{B}_{1} \sin \sigma t+\bar{C}_{1} \cos \sigma t\right) \cdots
$$

であるから，付加質量係数 $K_{x}$ と減衰力係数 $N_{x}$ は式

(70) に対応して次のようになる。

$$
K_{x}=\bar{C}_{1} / q, N_{x}=\bar{B}_{1} / q
$$

この減衰力係数と造波係数の関係は式 (73) に対応し て次のようである。

$$
\bar{B}_{1}=\frac{2}{\pi} \cdot \frac{N_{0}}{(k h)^{2}} \cdot \frac{\sigma^{2} h}{g} \cdot\left(\bar{K}_{1}{ }^{2}+\bar{L}_{1}{ }^{2}\right)
$$

\section{（3） rolling motionによる波の発生}

円柱が点 $\left(0,0, \bar{z}_{0}\right)$ を中心として $\delta=\delta_{0} \cos \sigma t$ で表 わされる横摇れを行なうときは, 速度 ポテンシャルは swaying motion の場合と同様に $m=1$ に対してのみ存 在し，その係数 $B_{10} / \delta_{0} \sigma a^{2}, C_{1 n} / \delta_{0} \sigma a^{2}$ および $D_{1 s} / \delta_{0} \sigma a^{2}$ を 決める連立方程式は式 (74) の右辺 $h^{(0)}, h^{(n)}$ の代りに $r^{(0)}, r^{(n)}$ とおけばそのまま用いられる。この場合は

$$
\left.\begin{array}{l}
\bar{g}_{0} \frac{B_{10}}{\delta_{0} \sigma a^{2}}+\sum_{n=1}^{\infty} \bar{g}_{n} \frac{C_{1 n}}{\delta_{0} \sigma a^{2}}=\bar{E}_{1}+i \bar{F}_{1} \\
\frac{B_{10}}{H_{1}{ }^{(2)}(k a) \delta_{0} \sigma a^{2}}=\bar{K}_{2}+i \bar{L}_{2} \\
\frac{D_{10}}{\delta_{0} \sigma a^{2}}+\sum_{s=1}^{\infty} \overline{f_{s}^{(2)}} \frac{D_{1 s}}{\delta_{0} \sigma a^{2}}=\bar{M}_{1}+i \bar{N}_{1} \\
2\left(\frac{a}{h}\right)^{2} \sum_{s=1}^{\infty} \frac{\operatorname{coth}\left(\bar{q} \lambda_{1 s} h / a\right)}{\lambda_{1 s}}=\bar{b}
\end{array}\right\}
$$

とおくと，点 $\left(0,0, \bar{z}_{0}\right)$ に関する,・円柱部分を流体でお きかえた場合の慣性能率は

$$
\begin{array}{r}
{\left[1+4\left\{\left(\bar{z}_{0} / a\right)^{2}+\left(\bar{z}_{0} / a\right)(q h / a)\right.\right.} \\
\left.\left.+(q h / a)^{2} / 3\right\}\right] \cdot \pi \rho a^{4} q h / 4
\end{array}
$$

であるから，造波係数 $\bar{A}_{\theta}$, 付加慣性能率㧍よび減衰力 モーメントの係数 $K_{\theta}, N_{\theta}$ はそれぞれ次式で表わされ る。

$$
\left.\begin{array}{rl}
\bar{A}_{\theta} & =\sqrt{\frac{r}{a}} \cdot \frac{|\zeta(r, 0)|}{\delta_{0} a}=\frac{\sigma^{2} h}{g} \cdot \frac{a}{h} \sqrt{\frac{2}{\pi k a}} \\
& \cdot\left(\bar{K}_{2}{ }^{2}+\bar{L}_{2}{ }^{2}\right)^{1 / 2} \\
K_{\theta} & =\frac{4}{q} \cdot \frac{h}{a} \cdot \frac{\bar{b}+\bar{F}_{1}+(a / h)^{2} \bar{N}_{1} / 4}{1+4\left\{\left(\frac{\bar{z}_{0}}{a}\right)^{2}+\frac{\bar{z}_{0}}{a} \frac{q h}{a}+\frac{1}{3}\left(\frac{q h}{a}\right)^{2}\right\}} \\
N_{\theta} & =\frac{4}{q} \cdot \frac{h}{a} \cdot \frac{\bar{E}_{1}+(a / h)^{2} \bar{M}_{1} / 4}{1+4\left\{\left(\frac{\bar{z}_{0}}{a}\right)^{2}+\frac{\bar{z}_{0}}{a} \frac{q h}{a}+\frac{1}{3}\left(\frac{q h}{a}\right)^{2}\right\}}
\end{array}\right\}
$$

また式 (82) に対応して次の関係がある。

$$
\bar{E}_{1}+\frac{1}{4}\left(\frac{a}{h}\right)^{2} \bar{M}_{1}=\frac{2}{\pi} \cdot \frac{a}{h} \cdot \frac{N_{0}}{(k h)^{2}} \cdot \frac{\sigma^{2} h}{g} \cdot\left(\bar{K}_{2}{ }^{2}+\bar{L}_{2}{ }^{2}\right)
$$

\section{4. 数值計算}

以上のすべての計算は式 (9) および (22) に仮定した 級数形の速度ポテンシャルとその勾配とが一様収束であ ることが前提とされるほか, 計算精度は級数項の数 $m$, $n$ および $s$ の大さに依存することになる。これらの点に ついては, Garret (1971) が固定した円柱に作用する波 の圧力の理論計算において検討しており, 同じことがこ こでも成立すると考えられる。実際上は $m, n, s$ の大さ をあまり大きく取ることは計算時間の上から不経済であ るため, ここでは $n=s=10$ までとし，こ礼に対して $m$ をそれぞれ 5,7 および 10 までとして， $a / h=0.5, q=$ 0.25 について $\sigma^{2} h / g=0.5,1.0$ および 1.5 に対して計 算し，その結果を境界条件式 (33) および (34) に代入 し, $z / h$ の種々の值についてこの条件が満たされる程度 を数值的に調べたが，その結果は $m=5$ までを取れば 実際上大きな誤差はないと判断される。この計算例 Table 1 に示すようで, $a / h=0.5, q=0.25, \sigma^{2} h / g=0.5$ （自由運動の場合）に対する境界条件式 (33)，(34)によ る $r=a, \theta=0^{\circ}$ および $180^{\circ}$ における水平流速と速度ポ テンシャルの無次元值 $\phi /\left(s_{0} g / \sigma\right)$ および $\partial \phi / \partial x /\left(s_{0} g k / \sigma\right)$ を $m=5$ までの場合につき, 数值的に示している。これ によると速度ポテンシャルは有効数字 3 けた, 水平流速 は $z=-q h$ の特異点付近を除いて 2 けたの程度まで一致 していることがわかる。

\section{（1）円柱浮体の自由運動}

2.の（7）において示した式で， $m$ を 5 まで， $n$ 㧍よ び $s$ を 10 まで取り, $\sigma^{2} h / g$ を 0.1 ごとに $0.1 \sim 4.0$ ま で変えて, 静止時の重心位置が静水面から (3/4) qh の梁 さにある場合につき $\nu^{2}=1, a / h=0.25$ および 0.50 亿対 し $q=0.25,0.50$ および 0.75 としたときの円柱重心の 水平変位と鉛直変位および回転角の絶対值を入射波振幅 により無次元化して表わすと Fig. 3 (a), (b), Fig. 4 (a)，(b) および Fig. 5 (a)，(b) のようである。これ らの結果によると次のことがわかる。

(1) swaying motionについては,振幅は frequency の増加とともに減少するが, 吃水が深いときは rolling motion との連成により rolling motion の振幅の peak において一つの極大振幅を示すことになる。円柱の直径 が大きくなっても振幅は多少小さくなるが，あまり変化 はなく, また rolling motion との連成は弱くなる。 
Table 1 Numerical Check on the Continuity of Velocity Potential and Horizontal Velocity for $\theta=0^{\circ}$ and $180^{\circ}$

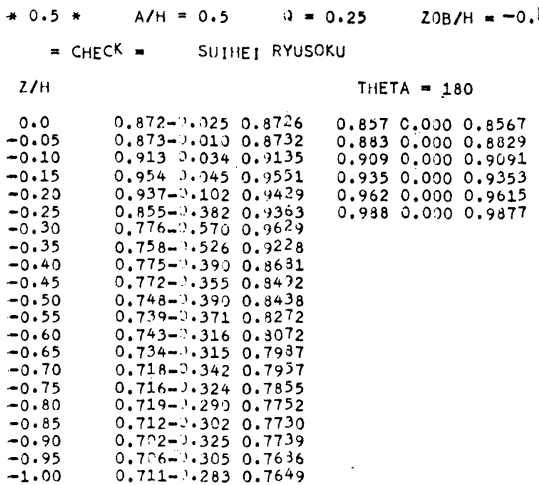

\begin{tabular}{|c|c|c|c|}
\hline & & THETA $=0$ & \\
\hline & & $\begin{array}{lll}-0.857-0.000 & 0.8567 \\
-0.883-0.000 & 0.8829 \\
-0.099-0.000 & 0.9091 \\
-0.935-0.000 & 0.9353 \\
-0.935-0.000\end{array}$ & 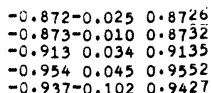 \\
\hline & $=0.575-1.247 \quad 1.3732$ & & $=0.854-0.3830 .93581$ \\
\hline 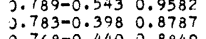 & $\begin{array}{lll}-0.788-0.544 & .95316 \\
-0.783-0.398 & 0.8780\end{array}$ & & $=0.758-0.526 \quad 0.9221$ \\
\hline $68=0.440 \quad 0.8849$ & $-0.767-0.4400 .8844$ & & $-0.775-0.39000 .8676$ \\
\hline 0.8662 & $756-0.4210 .8657$ & & $-0.771-0.355 \quad 0.8488$ \\
\hline $\begin{array}{rl}.340 & 0.8277 \\
.333 & 0.8230\end{array}$ & $0.754-0.3400 .8273$ & & $=0.748-0.390 \quad 0.8433$ \\
\hline $\begin{array}{l}753-0.333 \\
733-0.360\end{array} 0: 82.300171$ & $\begin{array}{lll}-0.752-0.333 & 0.8266 \\
-0.733-0.361 & 0.816\end{array}$ & & $\begin{array}{lll}-0.739-0.031 & 0.8268 \\
-0.742-0.317 & 0.8068\end{array}$ \\
\hline $724-0.3390 .7991$ & $\begin{array}{l}-0.723-0.339 \\
0.7987\end{array}$ & & $-0.733-0.3150 .7984$ \\
\hline $731-0.303 \quad 0.7911$ & 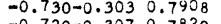 & & $\begin{array}{lll}-0.718-0.342 & 0.7953\end{array}$ \\
\hline 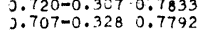 & $\begin{array}{ll}-0.720-0.307 & 0.7829 \\
-0.706-0.328 & 0.7789\end{array}$ & & $\begin{array}{ll}-0.715-0.324 & 0.7852 \\
-0.718-0.290 & 0.7749\end{array}$ \\
\hline $711-0.3140 .7770$ & $-0.711-0.314 \quad 0.7767$ & & $-0.711-0.302 \quad 0.7727$ \\
\hline 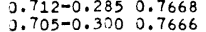 & 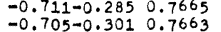 & & $\begin{array}{lll}-0.702-0.325 & 0.7735 \\
-0.705-0.305 & 0.7683\end{array}$ \\
\hline $0.703-0.324 \quad 0.7737$ & $\begin{array}{r}1 \\
.702-0.324\end{array}$ & & $\begin{array}{l}-0.105-0.303 \\
-0.710-0.283\end{array}$ \\
\hline
\end{tabular}

$=$ CHECK $=$ SOKIDO POTENTIAL

\begin{tabular}{|c|c|c|c|c|}
\hline $2 / H$ & \multicolumn{4}{|c|}{ THETA $=180$} \\
\hline & 0.3750 .873 & 0.7501 & & \\
\hline $\begin{array}{l}=0.10 \\
-0.10\end{array}$ & 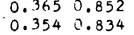 & $\begin{array}{l}0.970 \\
0.3057\end{array}$ & & \\
\hline & $\begin{array}{llll}0.344 & 7.82 J\end{array}$ & 0.3994 & & \\
\hline .25 & $\begin{array}{lll}0.036 & 0.813 \\
0.332 & 0.814\end{array}$ & 0.3792 & 0.3310 .814 & \\
\hline .30 & 0.3280 .811 & 0.8751 & $0.328 \quad 0.811$ & 0.8751 \\
\hline $\begin{array}{l}35 \\
.40\end{array}$ & $\begin{array}{l}0.333 \\
0.317 \\
0.801\end{array}$ & $\begin{array}{l}0.8377 \\
0.3484\end{array}$ & $\begin{array}{l}0.323 \\
0.317 \\
0.801\end{array}$ & $\begin{array}{l}0.8637 \\
0.8494\end{array}$ \\
\hline & $0.312 \quad 0.775$ & 0.8351 & 0.3120 .775 & 0.8351 \\
\hline & 0.3080 .765 & $\begin{array}{l}0.3244 \\
0.8135\end{array}$ & $0.307 \quad 0.765$ & 0.8244 \\
\hline & $\begin{array}{ll}0.03330 .755 \\
0.299 & 0.745\end{array}$ & $\begin{array}{l}0.8135 \\
0.8027\end{array}$ & $\begin{array}{l}0.303 \\
0.299 \\
0.755 \\
0.745\end{array}$ & $\begin{array}{l}0.8135 \\
0.8,726\end{array}$ \\
\hline & $0.296 \quad 0.737$ & 0.7941 & 0.2960 .737 & 0.7941 \\
\hline & 0.2930 .731 & i. $\begin{array}{l}\text { i. } 7873 \\
0.7807\end{array}$ & $0.294 \quad 0.731$ & 0.7873 \\
\hline & 0.2890 .719 & 0.7748 & 0.2890 .719 & 0.7748 \\
\hline & 0.2870 .715 & 0.7710 & $0.288 \quad 0.715$ & 0.7710 \\
\hline & $\begin{array}{lll}87 & 0.713 \\
86 & 0.711\end{array}$ & 0.087 & 0.2870 .713 & \\
\hline & 350.710 & 7655 & 0.2850 .710 & \\
\hline
\end{tabular}

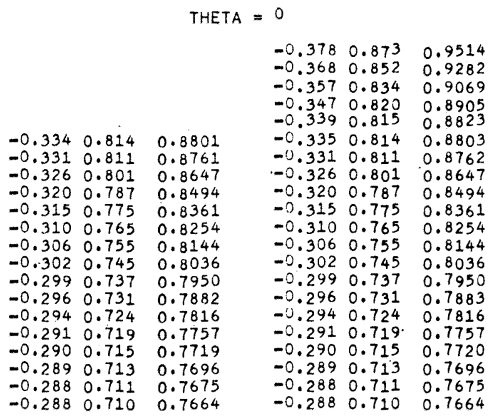

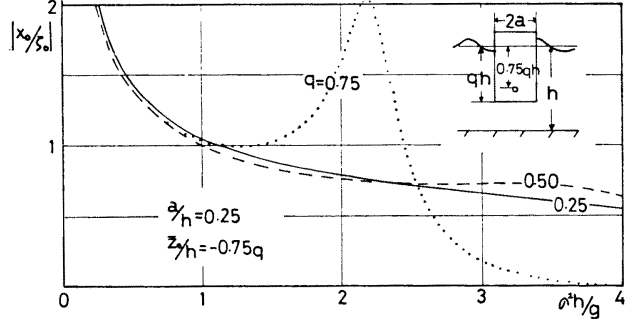

Swaying Amplitude of Freely Floating Cylinder

Fig. 3 (a)

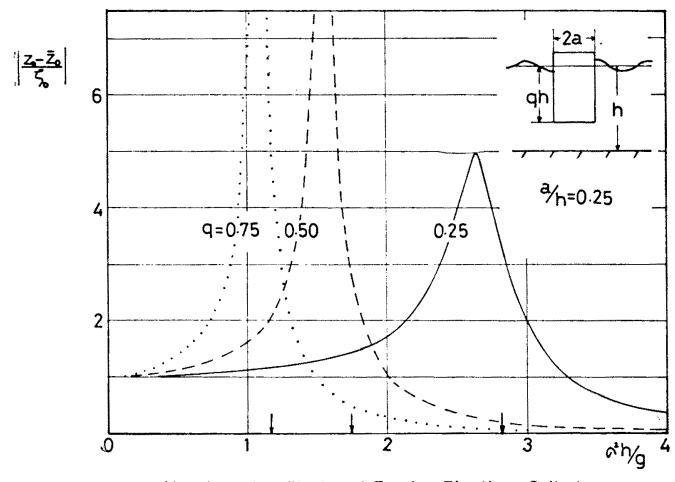

Heaving Amplitude of Freely Floating Cylinder

Fig. 4 (a)

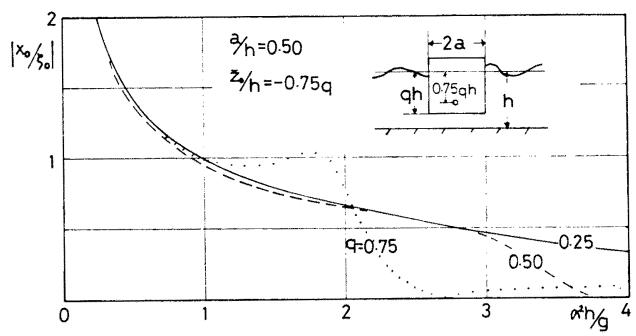

Swaying Amplitude of Freely Floating Cylinder

Fig. 3 (b)

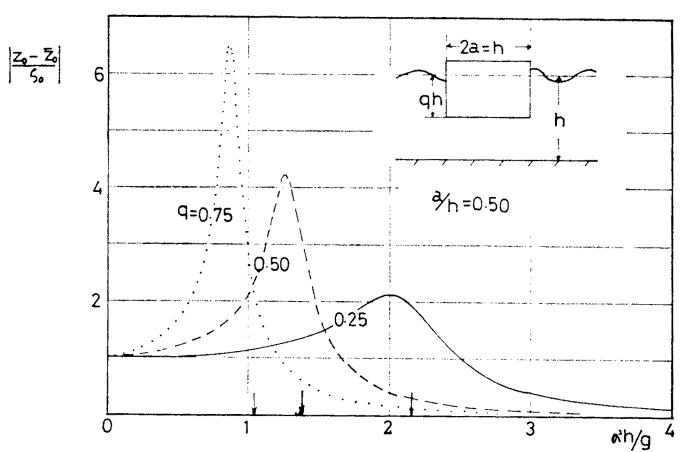

Heaving Amplitude of Freely Floating Cylinder

Fig. 4 (b) 


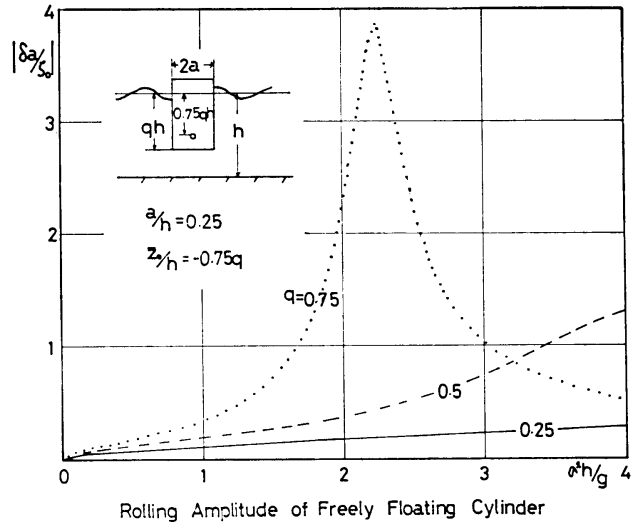

Fig. 5 (a)

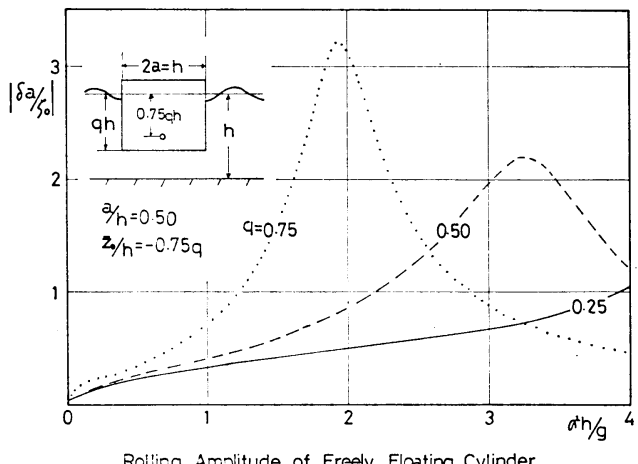

Fig. 5 (b)

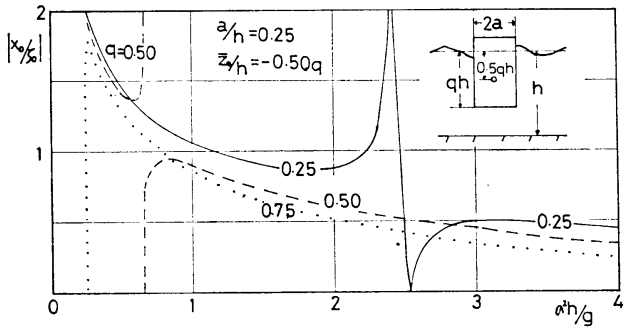

Swaying Amplitude of Freely Floating Cylinder

Fig. 6 (a)

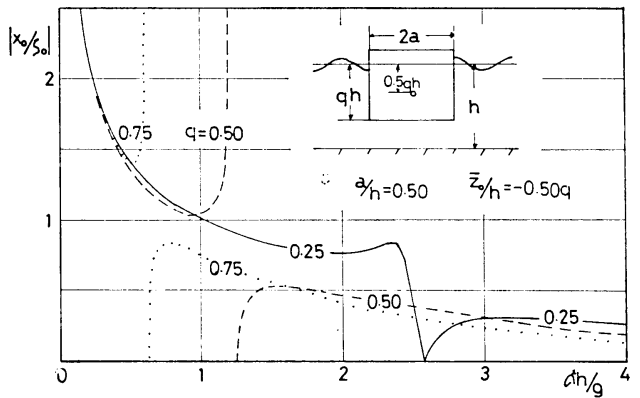

Swaying Amplitude of Freely Floating Cylinder

Fig. 6 (b)

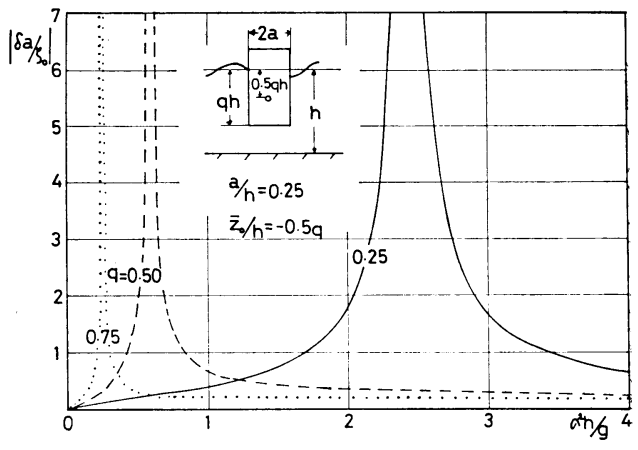

Rolling Amplitude of Freely Floating Cylinder

Fig. 7 (a)

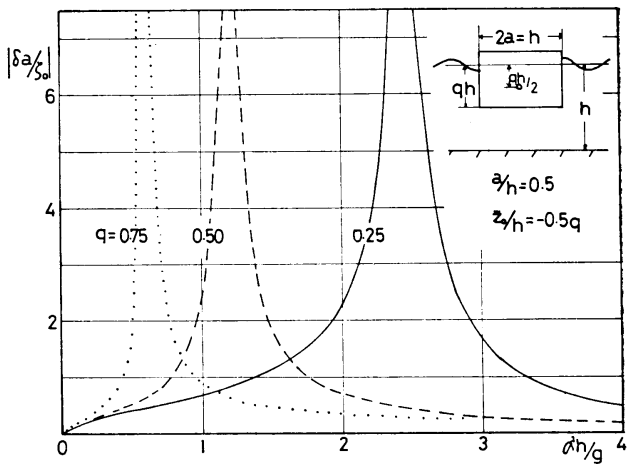

Rolling Amplitude of Freely Floating Cylinder

Fig. 7 (b)

frequency が 0 に近づくと振幅は見かけ上非常に大きく なるが，流体実質部分の水平移動量との比はほとんど 1 に等しくなる。

(2) heaving motion については, 吃水に対応した peak amplitude を示すが，吃水の増加とともに peak frequency は小さく amplitude は大きくなる。円柱直 径が大きくなると peak frequency も amplitude も小 さく運動は安定する。 heaving motion は swaying およ び rolling とは独立であるため peak frequency はそ れらと関係しない。

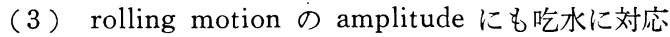
した peak が見られ，円柱直径が大きくなると peak の amplitude と frequency は小さくなる。

上と同じ条件で円柱重心が吃水のちょうど $1 / 2$ の梁さ にある場合を示すと Fig. 6 (a)，(b)，Fig. 7 (a), (b) のようである。この場合には次のことがわかる。

(4) heaving motion は重心位置に関係せず, 前の 場合と全く同じである。

(5) rolling motion $の$ peak amplitude は著しく 大きくなって運動は不安定に近づき, 同時に peak frequency は著しく小さい值に移る。また前の場合と異な り，直径が大きいときに peak frequency は大きくなり， 
その傾向は吃水の大きいときに著しい。

(6) swaying amplitude においては, rolling motion との連成によりその peak frequency に対応する frequency において不連続が現われるが，それを除くと 前の場合と類似の傾向を示す。

以上のような各運動の様子は前論文（井島他 1972）に 取扱った矩形断面浮体の 2 次元運動とかなり近似してい るが，円柱の直径と等しい幅の矩形断面浮体の運動と比 べると，他の条件が同じのときは次のような相違が見ら れる。

(7) heaving motion $の$ peak frequency は矩形断 面浮体のものよりやや大きくなり，特に amplitude は 2 倍程度となる。

(8) rolling motion $の$ peak frequency も矩形断 面のものより大きくなり, amplitude は吃水が大きいと き 2 倍程度になるが，吃水が小さいときは似た程度であ る。

(9) swaying motion の amplitude は矩形断面の ものときわめて近似しているが, rolling motion との連 成は矩形断面の場合よりも強い。

深海波における半径 $a$, 吃水 $l_{2}(=q h)$ の円柱の heaving motion の固有振動数 $\sigma_{0}$ は $\sigma_{0}{ }^{2} l_{2} / g \approx 1 /\left(1+\frac{4}{3 \pi} \cdot \frac{a}{l_{2}}\right)$ で表わされるから， $\sigma_{0}^{2} h / g \approx 1 / q\left(1+\frac{4}{3 \pi} \frac{a}{q h}\right)$ である。

Fig. 4 (a)，(b) の矢印はこの值を示したものである が，これからわかるように有限水深の波による peak frequency $\sigma_{0}$ よりや や小さい值を示すことに なる。これは後述する heaving motion に対す る付加質量倸数が深海波 条件におけるよりも大き な值を示すことによるも のである。

円柱浮体の運動は直径 が大きくなるとともに， peak frequency $\&$ amplitude も小さくなり，安 定に向うが，運動に対す る重心位置の変化の影響 は rolling motion 沉著 しく現われ，それに連成 して swaying motion 8 変わる。この傾向は矩形 断面浮体においても同様 であるが，円柱浮体に比 べるとその程度はかなり

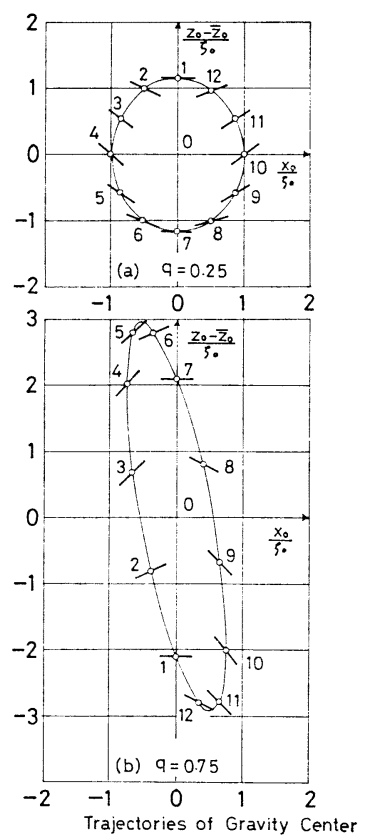
and Inclination of Cylinder, $0^{2} \mathrm{~h} / \mathrm{g}=1.0$ $a / h=0.5, \bar{z}_{0 / h}=-0.5 q, s_{0} / a=1.0$

Fig. 8
小さいといらことができる。

な押，式 (48)～(50) により重心位置の移動軌跡とそ の位置での円柱の傾きを $a / h=0.5$ の円柱に対し, 重心 が吃水の半分の位置にあるとき $\left(\bar{z}_{0} / h=-0.5 q\right)$ を $\sigma^{2} h /$ $g=1.0$ の波に対して $\zeta_{0} / a=1.0$ として計算すると Fig. 8 のよらである。ここでは静止時の重心位置を原点とし $\sigma t=0^{\circ}$ から $360^{\circ}$ までの $30^{\circ}$ ごとの位置をそれぞれ 1 , $2,3 \cdots 12$ の点で示し, 各点での傾き $\delta$ を実線で示して いる。入射波は図の右加左へ進行し， $\sigma t=0^{\circ}$ (点 1) および $180^{\circ}$ (点 6 ) においてそれぞれ山および谷が現わ れる。図に見るようにこの場合は吃水が浅いとき $(q=$ 0.25）には重心の軌道は円に近い棈円で反時計回りとな り，傾きは通過する波の水面勾配 ( $\partial \zeta / \partial x)$ の変化と類 似であるが，吃水が深いとき $(q=0.75)$ は，傾斜した細 長い楕円軌道となり，時計回りで，傾きは波の水面勾配 と反対の変化を示すことになる。このような重心の軌跡 と傾きの変化は円柱の形と波の性質に応じて変わるもの である。

\section{（2）円柱浮体の繫留運動}

繋留浮体の運動は繋留の方式によって著しい相違を示 すことになるが，ここでは Fig. 2 (b) に示すように円 柱下端をば社定数 $K=0.5 \rho g \pi a^{2}$ をもつ 2 本の spring で cross type の慗留をした場合を考え， $a / h=0.25, \mu=$

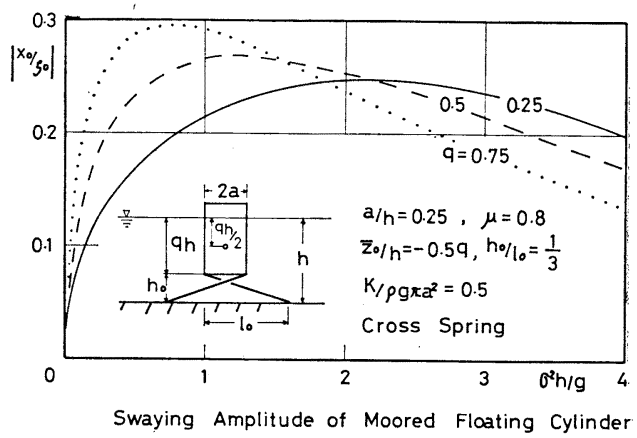

Fig. 9

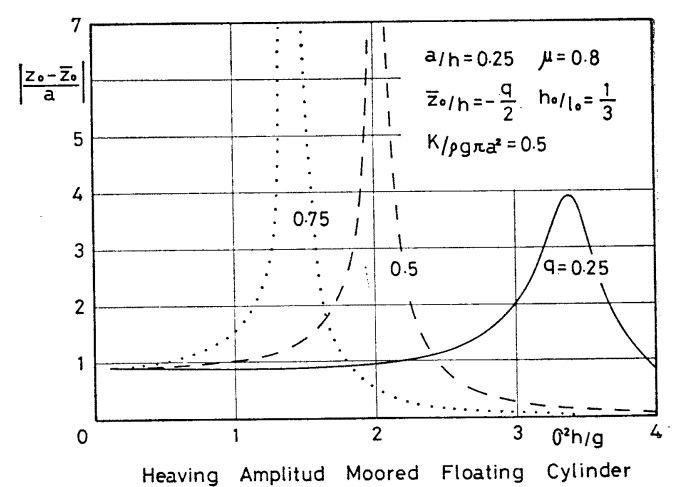

Fig. 10 
0.8 とし, 静止時の浮体重心が吃水の $1 / 2$ にあり, 繋留 スプリングは $h_{0} / l_{0}=1 / 3$ の関係にあるとする。計算の結 果円柱重心の水平変位と鉛直変位および回転角を示すと Fig. 9, 10 および 11 のようである。自由浮体の場合と 比べると, swaying および rolling の amplitude は著 しく小さくなるとともに, rolling の peak amplitude は消滅し，したがって swaying amplitude の不連続も なくなり，frequency による変化は著しく滑らかとな

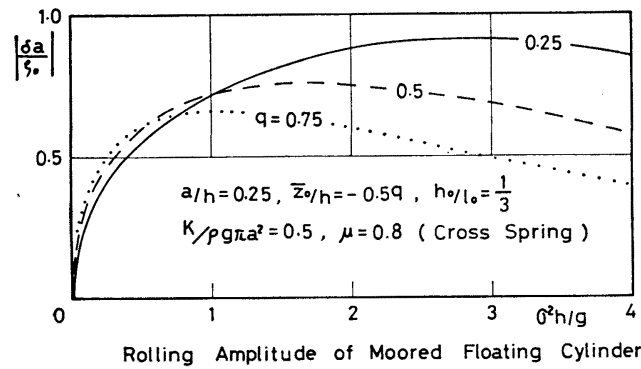

Fig. 11

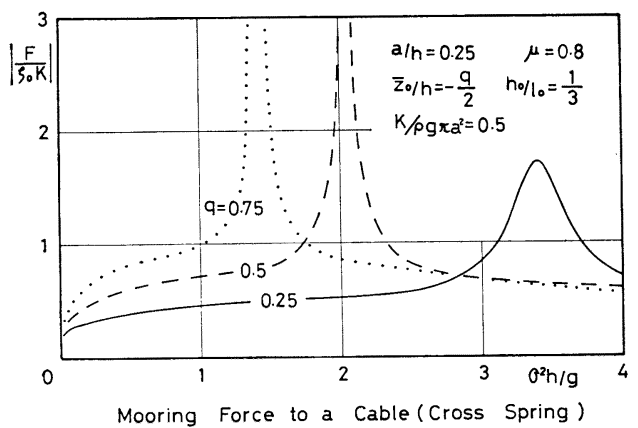

Fig. 12

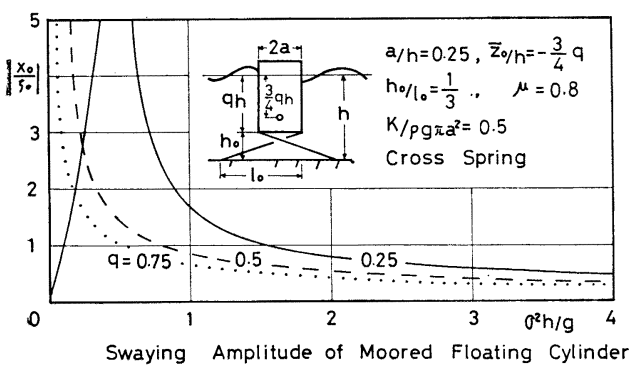

Fig. 13

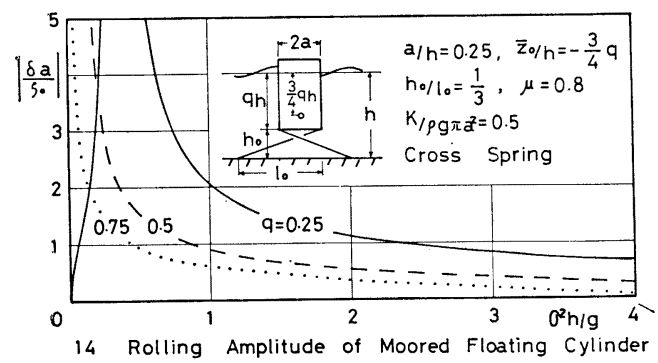

Fig. 14
る。 heaving amplitude $の$ peak frequency は自由浮体 の場合よりも大きな值に移り, amplitude も小さくな る。この場合 1 本の蒰留索（spring）に作用する力を式 （60）により計算すると Fig. 12 のようで，最大の力は heaving motion に支配されて生ずることがわかる。

このような運動形式は浮体重心の位置によって影響さ れることが大きく，たとえば同じ条件で浮体重心が吃水 の $3 / 4$ の深さにあるときを計算すると heaving motion は全く同じで変化はないが， swaying と rolling とは Fig. 13,14 に示すように frequency の小さい所に著し い peakを示すようになり,前の場合に比べて amplitude は全体的にかなり大きくなる。これと heaving motion との効果によって熬留索に作用する力は Fig. 15 に示

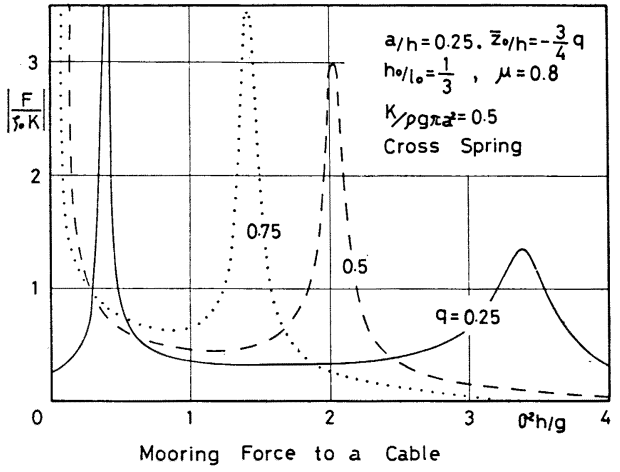

Fig. 15

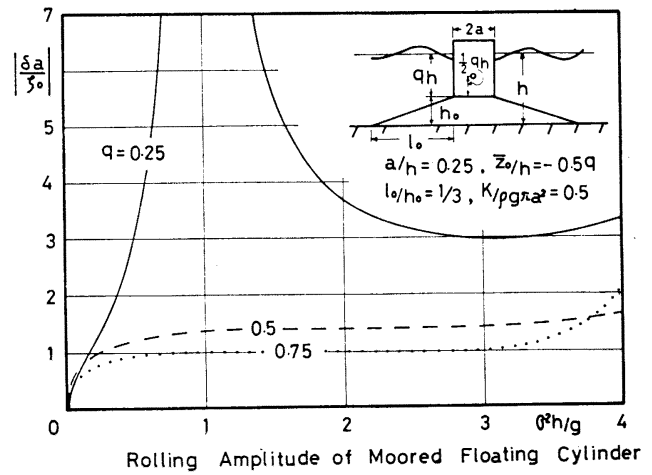

Fig. 16

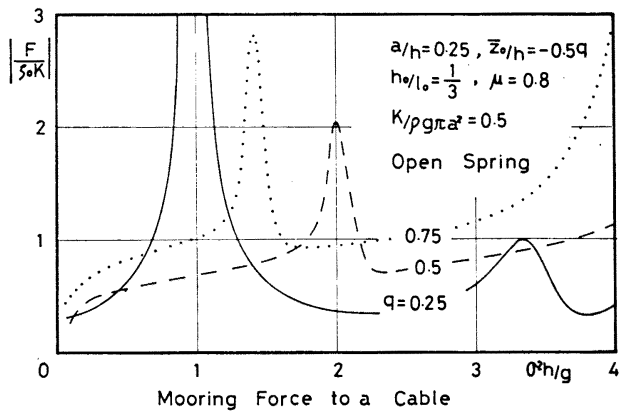

Fig. 17 
すように heaving と rolling の peak frequency で極 大を示すこととなる。

open type の慗留の例として Fig. 9 と同じ形の円柱 についての計算例を rolling motion について示すと

Fig. 16 のようで吃水によって amplitude 著しい変 化があることがわかる。 heaving motion は Fig.10 と 全く同じで swaying motion は Fig. 16 と類似の変化 を示すことになる。1本の索に作用する力は, Fig. 17 のようである。

\section{（3）円柱の強制運動による波の発生と圧力}

3. に述べた方法によって $a / h=0.25$ の円柱に対し $q=$ ๒.25, 0.50 および 0.75 について heaving, swaying お

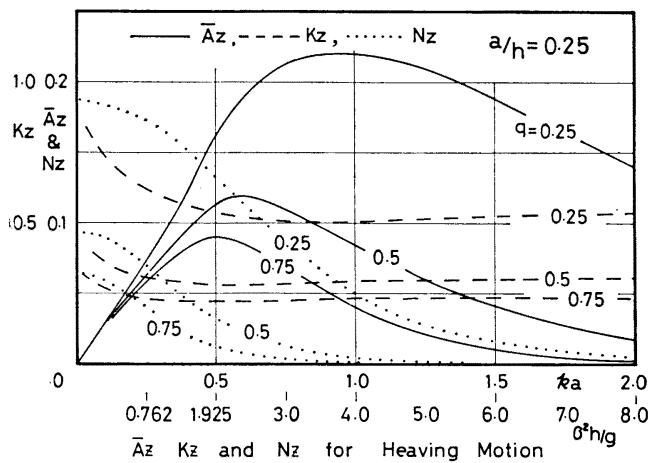

Fig. 18

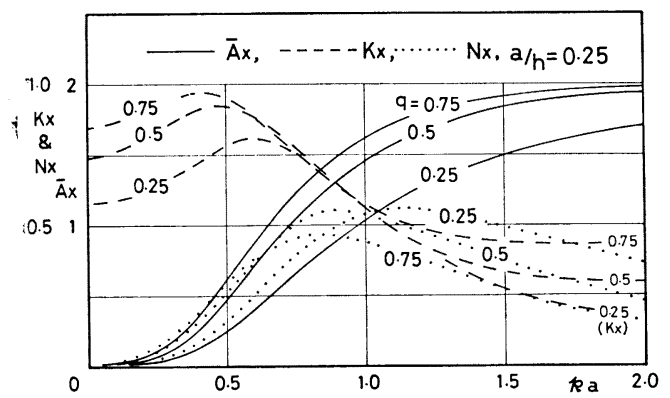

$\bar{A} x, K x$ and $N x$ for Swaying Motion

Fig. 19

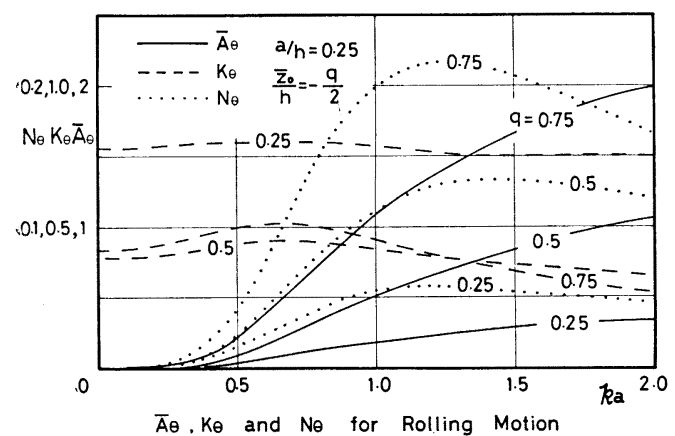

Fig. 20
よび吃水の $1 / 2$ の点を中心として rolling motion を強 制した場合の造波係数 $\bar{A}$, 付加質量係数 $K$ および減衰 力倸数 $N$ を計算するとそれぞれ Fig. 18, Fig. 19 お よび Fig. 20 のようである。この計算による造波係数 は Black, $\mathrm{Mei}^{3}$ らによる変分法計算の結果と全く一致 する（変分法においては $K$ および $N$ を計算すること はできない)。なお，本計算における検証式 (73)，(82) および (85) は有効数字 2 けた以上の程度で一致する。 これらの結果からいずれの運動に対しても付加質量と減 衰力は frequency の関数として取り扱わ视ばならないこ とがわかる。

\section{5.むすび}

以上述べたところから, 円柱浮体の運動に関しては次 のように考えることができる。

（1） 円柱浮体が有限水深の波によって自由運動を行 なう場合には, heaving motion は swaying 抢よび rolling motion と独立な運動であるため, 浮体重心の位置 に関係せず，矩形断面浮体と類似の性質を示し， peak amplitude の frequency は, 無限水深の場合に近いが, それよりもやや小さい值を示すことになる。またこれら の peak amplitude は浮体吃水と水深の比が大きくなる とともに大きな值を示すようになる。 rolling motion は 浮体重心の深さによって著しい影響をうけ peak amplitude の大さと frequency は重心位置の変化によりはな はだしく変わる。これはおもに重心の深さによる復元力 の変化が大きいことによるものである。 swaying motion は rolling motion との連成のため, rolling motion peak frequency の付近で特異な変化を示すこととなる が, 他の frequency においては, その増加とともに amplitude は減少し, またその值は吃水や円柱の直径の 変化にはあまり大きな影響をうけない。

これを要するに円柱の自由運動では heaving motion はその外形（すなわち, 直径と吃水）により決まり, swaying motion は流体実質部分の水平変位に支配され るところが大きいため, 外形の変化による影響は最も小 さく, rolling motion は外形の外に重心位置の影響を最 も強く受け，それが swaying motion にも現われるこ とになると見ることができる。

（2） 円柱浮体の骜留運動においては, heaving motion 以外の運動は熬留条件と円柱の外形および重心位置 により著しく変わり, 自由運動との関連から簡単に運動 を予想することはきわめて危険である。

（3） 円柱の強制運動による発生波および流体圧力 は, 円柱の外形の外に, frequency によって大きく変化 する。このため円柱運動に対する付加質量と減衰力係数 
は一般にこれを frequency の関数として取り扱わねば ならない。

以上の結果は, 完全流体における速度ポテンシャルを もつ微小振幅波の仮定に基づくものであるが，実際には 運動に対する粘性抵抗があり, またそうでなくても, 自 由運動においては㳯体の漂流現象が現われることになる が，その効果はもちろん本文では考慮していない。これ らの点を考慮しながら，上記の結果を実験的に確かめる 必要があり，現在進行中である。

本論文の作成に当たり，計算整理および図面作成を担 当した本学研究補助員 坂井久雄氏に厚く感謝の意を表
すものである。

\section{参考文 献}

1) Miles, J. and F. Gilbert : Scattering of Gravity Waves by a Circular Dock, Journal of Fluid Mech., Vol. 34, part. 4, 1968.

2) Garret, C.J.R. : Wave Forces on a Circular Dock, J.F.M. Vol., 46, part 1, 1971.

3) Black, J.L., C.C. Mei and M.C.G. Bray : Radiation and Scattering of Water Waves by Rigid Bodies, J.F.M., Vol. 46, part 1, 1971.

4) 井島武士・田㴊幹修・湯村やす：有限水深の波による矩 形断面物体の運動と波の変形, 土木学会論文報告集, 第 202 号, 1972 年 6 月.

(1972. 4. 25 - 受付) 